\title{
COVID-19 length of hospital stay: a systematic review and data synthesis
}

\author{
Eleanor M. Rees ${ }^{1 *}$ (D) $^{\dagger}$, Emily S. Nightingale ${ }^{2 \dagger}$, Yalda Jafari $^{1}$, Naomi R. Waterlow ${ }^{1}$, Samuel Clifford ${ }^{1}$, \\ Carl A. B. Pearson ${ }^{1,3}$, CMMID Working Group $^{1}$, Thibaut Jombart ${ }^{1,4,5}$, Simon R. Procter ${ }^{1 \dagger}$ \\ and Gwenan M. Knight ${ }^{1+}$
}

\begin{abstract}
Background: The COVID-19 pandemic has placed an unprecedented strain on health systems, with rapidly increasing demand for healthcare in hospitals and intensive care units (ICUs) worldwide. As the pandemic escalates, determining the resulting needs for healthcare resources (beds, staff, equipment) has become a key priority for many countries. Projecting future demand requires estimates of how long patients with COVID-19 need different levels of hospital care.
\end{abstract}

Methods: We performed a systematic review of early evidence on length of stay (LOS) of patients with COVID-19 in hospital and in ICU. We subsequently developed a method to generate LoS distributions which combines summary statistics reported in multiple studies, accounting for differences in sample sizes. Applying this approach, we provide distributions for total hospital and ICU LOS from studies in China and elsewhere, for use by the community.

Results: We identified 52 studies, the majority from China (46/52). Median hospital LoS ranged from 4 to 53 days within China, and 4 to 21 days outside of China, across 45 studies. ICU LoS was reported by eight studies-four each within and outside China — with median values ranging from 6 to 12 and 4 to 19 days, respectively. Our summary distributions have a median hospital LoS of 14 (IQR 10-19) days for China, compared with 5 (IQR 3-9) days outside of China. For ICU, the summary distributions are more similar (median (IQR) of 8 (5-13) days for China and 7 (4-11) days outside of China). There was a visible difference by discharge status, with patients who were discharged alive having longer LoS than those who died during their admission, but no trend associated with study date.

Conclusion: Patients with COVID-19 in China appeared to remain in hospital for longer than elsewhere. This may be explained by differences in criteria for admission and discharge between countries, and different timing within the pandemic. In the absence of local data, the combined summary LoS distributions provided here can be used to model bed demands for contingency planning and then updated, with the novel method presented here, as more studies with aggregated statistics emerge outside China.

Keywords: Hospitalisation, ICU capacity, COVID-19, SARS-CoV-2, Bed demand, Length of stay

\footnotetext{
*Correspondence: eleanor.rees1@lshtm.ac.uk

Simon R. Procter and Gwenan M. Knight are joint senior authors.

${ }^{\dagger}$ Eleanor M. Rees, Emily S. Nightingale, Gwenan M. Knight and Simon R.

Procter contributed equally to this work.

'Department of Infectious Disease Epidemiology, London School of Hygiene

and Tropical Medicine, Keppel Street, London, UK

Full list of author information is available at the end of the article
}

(c) The Author(s). 2020 Open Access This article is licensed under a Creative Commons Attribution 4.0 International License, which permits use, sharing, adaptation, distribution and reproduction in any medium or format, as long as you give appropriate credit to the original author(s) and the source, provide a link to the Creative Commons licence, and indicate if changes were made. The images or other third party material in this article are included in the article's Creative Commons licence, unless indicated otherwise in a credit line to the material. If material is not included in the article's Creative Commons licence and your intended use is not permitted by statutory regulation or exceeds the permitted use, you will need to obtain permission directly from the copyright holder. To view a copy of this licence, visit http://creativecommons.org/licenses/by/4.0/. The Creative Commons Public Domain Dedication waiver (http://creativecommons.org/publicdomain/zero/1.0/) applies to the data made available in this article, unless otherwise stated in a credit line to the data. 


\section{Background}

As of April 28, 2020, there have been over 3 million confirmed cases of COVID-19 and more than 200,000 deaths across 185 countries and territories [1]. Health systems are challenged by the influx of patients as SARS-CoV-2, the pathogen causing COVID-19, has spread throughout the world since its emergence in late December 2019 [2-6]. The risks of healthcare services being overwhelmed were most dramatically illustrated in Italy, where a rapid increase of COVID-19 cases needing hospitalisation pushed a well-equipped health system of 3.2 hospital beds per 1000 people to breaking point [7]. This raises serious concerns over the potential impact on more resource-constrained health systems in low- and middleincome countries (LMICs) as epidemics begin to expand across Africa and South America.

Understanding and predicting hospital bed demand (as well as associated staff or equipment requirements) provide crucial evidence for decision-making and contingency planning $(7,8)$. Predicting demand for hospital services requires an estimate of the number of patients requiring hospitalisation and an estimate of how long each person will require hospital care. It is possible to model the rate of hospitalisation in many settings based on estimated epidemic curves. However, estimating length of stay (LoS) in hospitals requires observation of individual patient pathways.

COVID-19 presents at varying levels of severity. Hospital care can vary from general ward-based care to high dependency units with oxygen support to intensive care where patients may be intubated for mechanical ventilation [8-10]. The LoS is likely to depend on the level of care required, as well as the geographic setting due to varying COVID-19 care guidelines. For example, some hospitals in China were initially used as isolation settings $[11,12]$. As knowledge of effective treatments changes, the pathways, staff, beds, and equipment required are also likely to affect the duration and level of care needed. Moreover, patient characteristics-such as age and comorbiditiesimpact disease severity $[8,12-14]$ and are likely to influence LoS. If differences are significant, then capacity planning may need to account for these characteristics to provide accurate predictions of the number of beds required at each level of care. Modelling studies predicting bed occupancy published so far have broadly relied on very few sources of information for LoS estimates, which were often derived from very different settings [15-22]. Estimates for LoS can be obtained from a variety of studies, but are often an incidental result rather than a study's primary outcome, and typically, only summary statistics are reported. In general, LoS distributions are right-skewed due to a minority of patients with long hospital stays and are often modelled using gamma, log-normal, or Weibull distributions [23] (although log-normal is less preferred due to its heavier tails). A particular challenge is how to synthesise appropriate $\operatorname{LoS}$ distributions from a range of relevant sources in similar settings, capturing the variation both within and between them. Incorporating the uncertainty and stochasticity in parameters using a distribution, rather than fixed point estimates (such as the mean over all studies), allows for more realistic model predictions.

We performed a systematic review to identify the current evidence on LoS for COVID-19 patients worldwide. We also present a method for generating LoS summary distributions by combining information from different summary statistics (mean and medians) reported in multiple studies, and accounting for differences in sample sizes. This aims to include all the variation between studies, to obtain a distribution that covers all plausible LoSs. Although similar in the sense of synthesising multiple sources, this is unlike a classic meta-analysis which aims to get a more precise estimate of a quantity assumed as being a fixed point value. In doing this work, we aim to inform the efforts of modellers and policy makers to better anticipate healthcare needs during the evolving COVID-19 pandemic.

\section{Methods}

\section{Search strategy}

This study was conducted following the Preferred Reporting Items for Systematic Reviews (PRISMA) guidelines (9). We searched the bibliographic databases Embase and Medline, as well as the online pre-print archive medRxiv. The latter was expected to be an important source due to the current rapid development of this field; hence, the fully published literature would capture only a small proportion of the available information. We included articles published up to 12 April 2020 that reported a LoS for COVID-19 patients admitted to hospital. To ensure all relevant papers were captured, we examined the title, abstract, and keywords of known studies reporting LoS to identify relevant search terms. Our search combined the concepts of COVID-19 (coronavirus, COVID-19, 2019nCov, and SARS-CoV-2) with search terms related to duration of hospital stay (length of stay, admission duration, admission length, hospital ${ }^{*}$ ). The search terms for hospital stay length were kept broad to capture studies that report LoS as a secondary outcome. The full search terms for Embase, Medline, and medRxiv are presented in the supplementary materials. In addition to our systematic searches, we also checked situation reports from the following organisations to see if they reported LoS estimates: UK Intensive Care National Audit and Research Centre (ICNARC), International Severe Acute Respiratory and Emerging Infection Consortium (ISARIC), World Health Organization (WHO), the US Centers for Disease Control and Prevention $(\mathrm{CDC})$, and China $\mathrm{CDC}$ and European CDC (ECDC). 


\section{Inclusion and exclusion criteria}

Inclusion criteria are as follows:

1 Studies that reported LoS in hospital for individuals who were admitted for confirmed COVID-19, or suspected COVID-19 which was later confirmed

2 Published (either as a pre-print or publication) between 1 January 2020 and 12 April 2020

Exclusion criteria are as follows:

1 Studies were excluded if LoS was reported for individuals only admitted to hospital for a reason other than confirmed or suspected COVID-19

2 Studies where the LoS endpoint was not death or discharge or continuing stay, for example, transfer to another hospital

3 Studies which stated that hospitalisation was used as a form of isolation

4. Studies not published in English

5 Review articles

\section{Screening}

The screening process is summarised in Fig. 1. All titles and abstracts were screened independently by two reviewers (EMR and SRP). Subsequently, abstracts and full texts of potentially relevant papers were independently reviewed by two reviewers (EMR and YJ).

\section{Data extraction and analysis}

The data that was extracted from each study is presented in Supplementary Table A. Data extraction was performed by EMR, YJ, and ESN and then verified by a second member of the study team. Study characteristics (such as study dates, study population, and study design) were recorded from each study, including information on the LoS sample estimate for both total hospital LoS and intensive care unit (ICU) LoS, as well as sample size, discharge status, and completeness of follow-up. If multiple LoS estimates were reported for different study populations, these were all recorded (for example, LoS reported by disease severity, comorbidities, and treatment groups). One study specified non-ICU LoS, and this was grouped with total LoS estimates; ICU LoS was reported separately. Average patient age and sex distribution (\% male) were summarised across all studies by weighted mean and standard deviation (mean (SD)), according to study sample size. Where possible, LoS estimates were recorded as median and interquartile range (IQR). Otherwise, mean and SD, or in some cases, only a point estimate was provided.

An assessment of bias was considered in these studies. Reported LoS in the majority of studies was not the primary outcome; therefore, a formal quality appraisal was not considered appropriate. Instead, we considered biases which may directly affect reported LoS. Studies were assessed as to whether follow-up had been completed for all included patients, such that an outcome of discharge or death had been observed for all and none remained in hospital at the end of the study. If this was not the case, the final summary of LoS may be biassed by including only shorter stays which were resolved within the time frame. As reported above, summaries of patient characteristics and comorbidities were recorded for each study where possible; this allowed later comparison of estimates based on features of the study population and provided some additional context with which to interpret the LoS estimates. Finally, the risk of bias related to potentially overlapping populations was also considered. Studies from the same hospital over the same time period were identified, and the study with largest sample size was selected from that group. A list of these studies is presented in Supplementary table B. LoS was then summarised including only these selected studies from the overlapping groups, along with the other non-overlapping studies. This estimate was then compared to the estimates based on all studies.

\section{Estimating LoS distributions}

Overall summary distributions were created for total hospitalisation LoS and for ICU LoS. Unlike a meta-analysis, the assumption here was not that each study had estimated an average LoS with some error, but that each study had captured a portion of the overall LoS distribution across a general population. Each of the studies provides us with a "sample" which we use to generate a better idea of the "true" underlying distribution. Our aim was to therefore incorporate all the variation across studies in order to obtain a distribution covering all plausible LoS values. We included studies in the estimation of these summary distributions if they reported both the sample size along with either the median and IQR or the mean and standard deviation. If no measure of variation was provided (either IQR or standard deviation), the point estimates were included in figures but excluded from these summary results.

Weibull distributions were fitted to the summary data from each study, using Nelder-Mead optimisation (implemented in the stats package in R [24]) for those reporting medians and IQRs. Specifically, the shape and scale parameters were varied in order to minimise the squared distance between the distribution and study quantiles. Where estimates were presented as a mean, $x$, and standard deviation, $s$, the distribution was fitted by momentmatching using the mixdist package [25]. The same approach was also tested using gamma distributions, but Weibull was marginally preferred with respect to total squared error in the fitted quantiles. These distributions were then discretised using the distcrete package in $\mathrm{R}$ [26]. A total of 100,000 samples were then drawn from each 


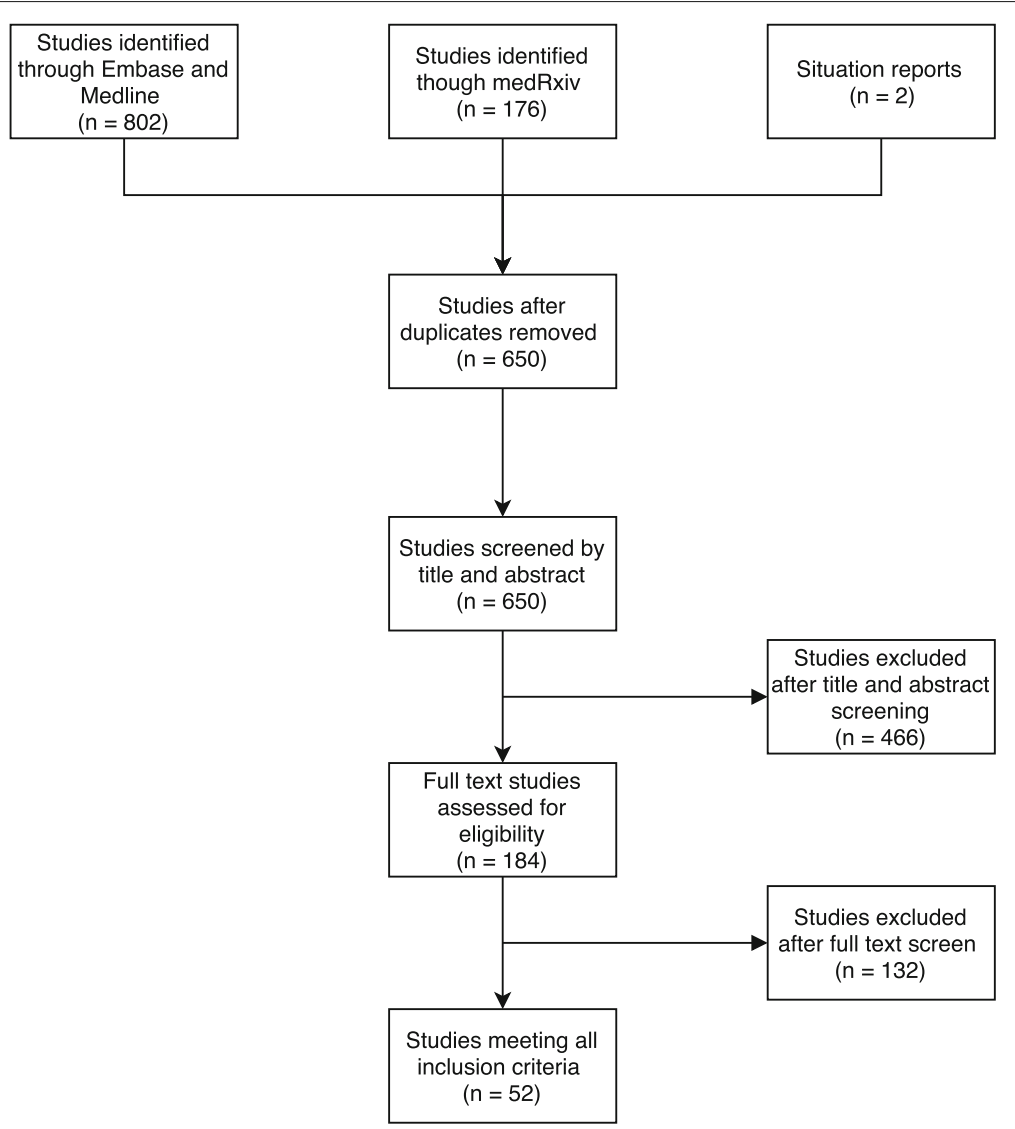

Fig. 1 PRISMA diagram showing the results of the screening process used to identify included studies $(n=52)$

of these distributions, with weighting according to their sample size. Specifically, the study distributions were first sampled according to a multinomial distribution defined by the studies' relative sample sizes, and LoS was then sampled from each of these sampled distributions. Due to potential important differences in the characteristics of each study population, it may not be appropriate to weight entirely on sample size without considering how representative the cohort is of the general population. Therefore, as a sensitivity analysis, we performed the same analysis without weighting in order to understand how much this influences the distribution. In some cases, studies reported LoS according to some stratification and not over the whole study population. Here, we applied the same method to summarise across the strata and obtain an estimated median and IQR across the whole population, validating the approach using examples where the overall summary statistics were also provided.

All analyses were performed using $\mathrm{R}$ version 3.6 .3 (29 February 2020).

\section{Results}

\section{Study characteristics}

The results of our screening process are summarised in Fig. 1. After removing duplicates, we found a total of 650 potentially eligible studies of which 52 studies met all the inclusion criteria. These included 32 peer-reviewed articles from the academic literature, 18 pre-print articles, and 2 reports from other sources ([27] and [28]). Several studies reported LoS by specific patient subgroups, according to disease severity, comorbidities (kidney injury, liver injury, hypertension, and cardiac injury), experimental treatments (heparin, lopinavir-ritonavir), and pregnancy status. A complete description of all reported LoS estimates is provided in Supplementary Table B. The key characteristics of the included studies are summarised in Table 1.

The studies were carried out between 24 December 2019 and 16 April 2020. Although the cut-off was 12 April 2020 for inclusion of published and pre-print studies, the most recent version of the ICNARC report [28] was used, which included patients admitted up to 16 April 2020. The majority of studies were cohort studies (46/52), with four cross-sectional studies, one case-control, and one randomised control trial (RCT). Two articles were reports from ongoing data collections (ISARIC [27], 8 April 2020, and ICNARC [28], 16 April 2020).

Studies were mostly conducted in adults with average participant age from 19 to 76 years (mean (SD) across 


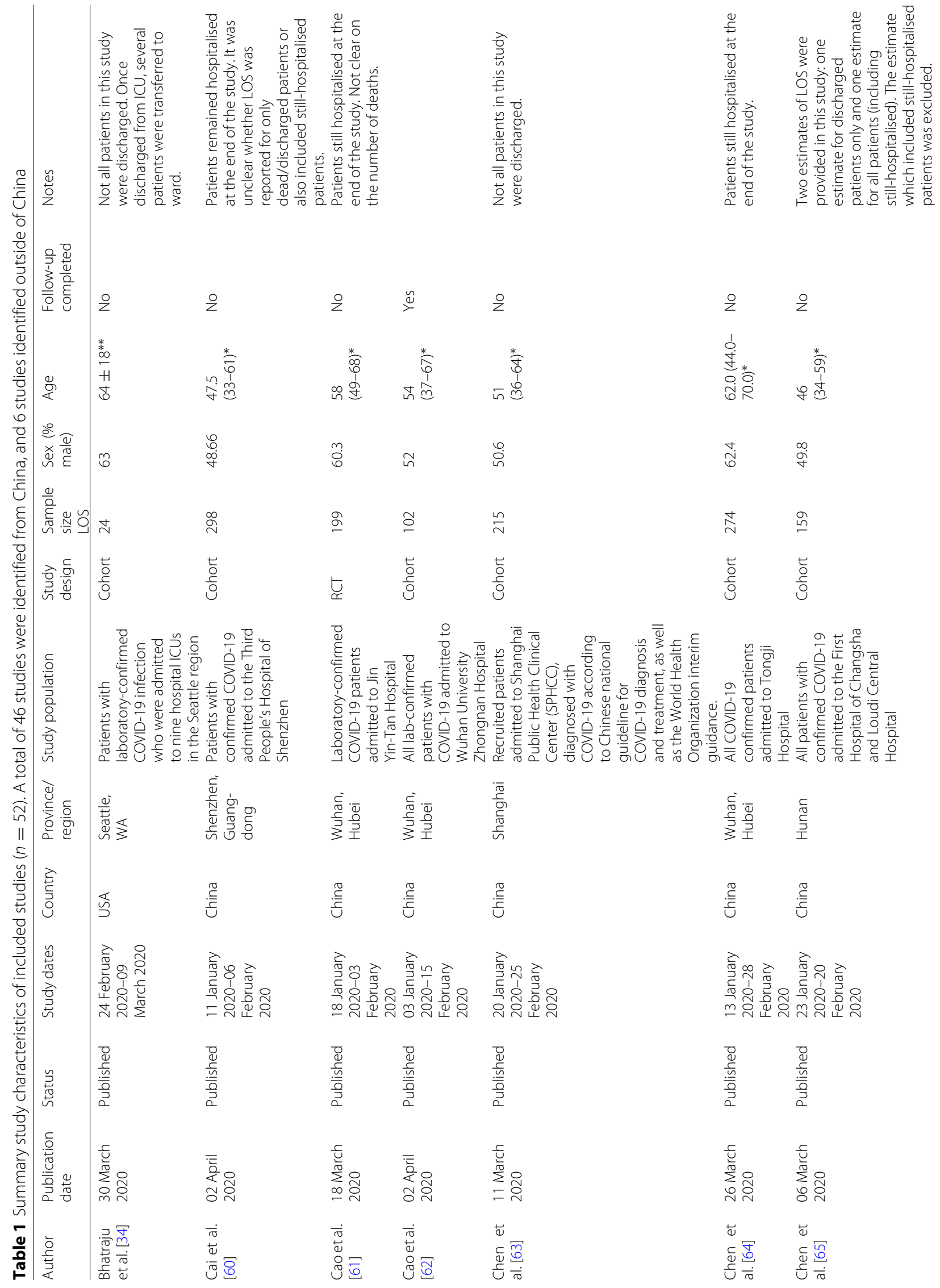




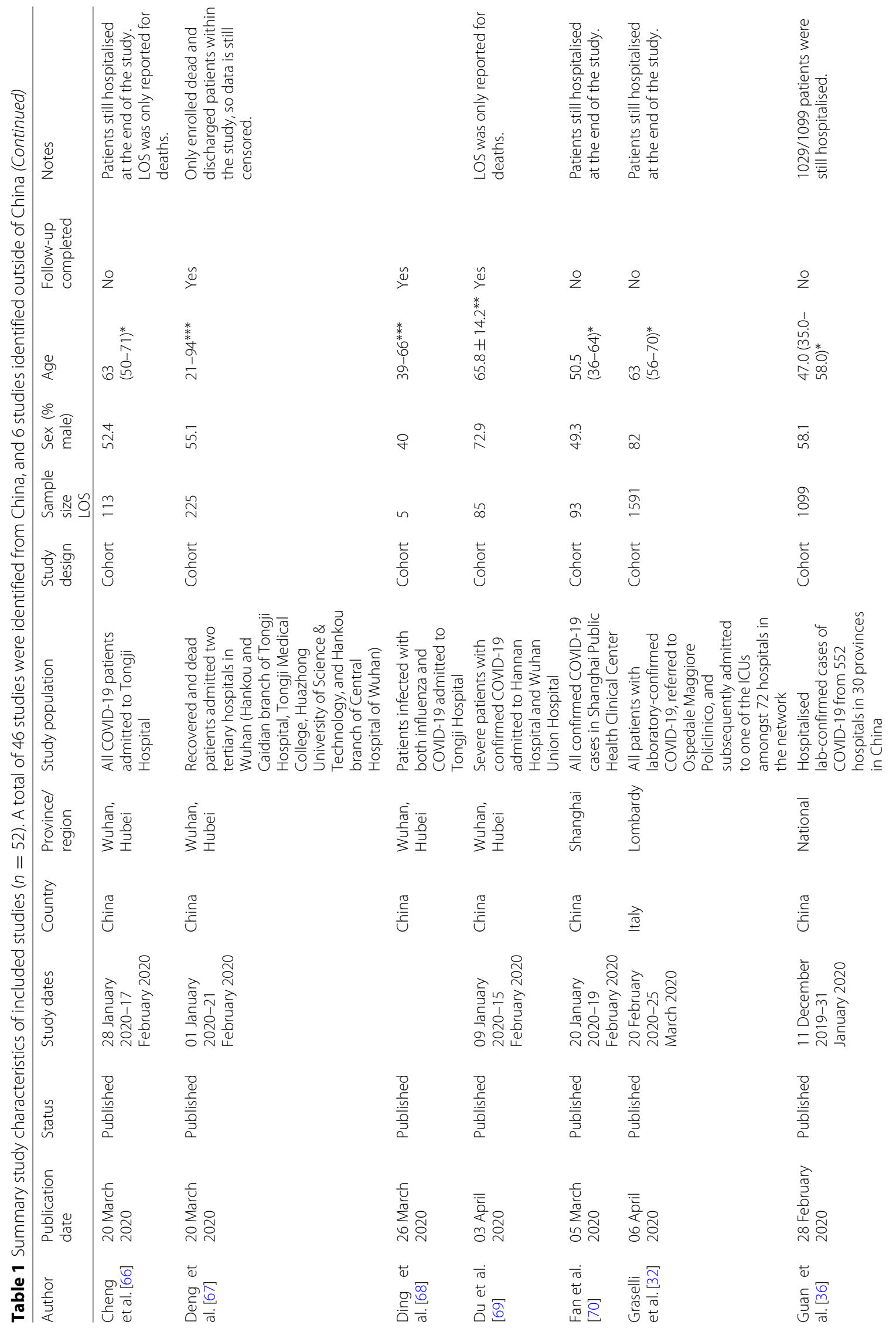




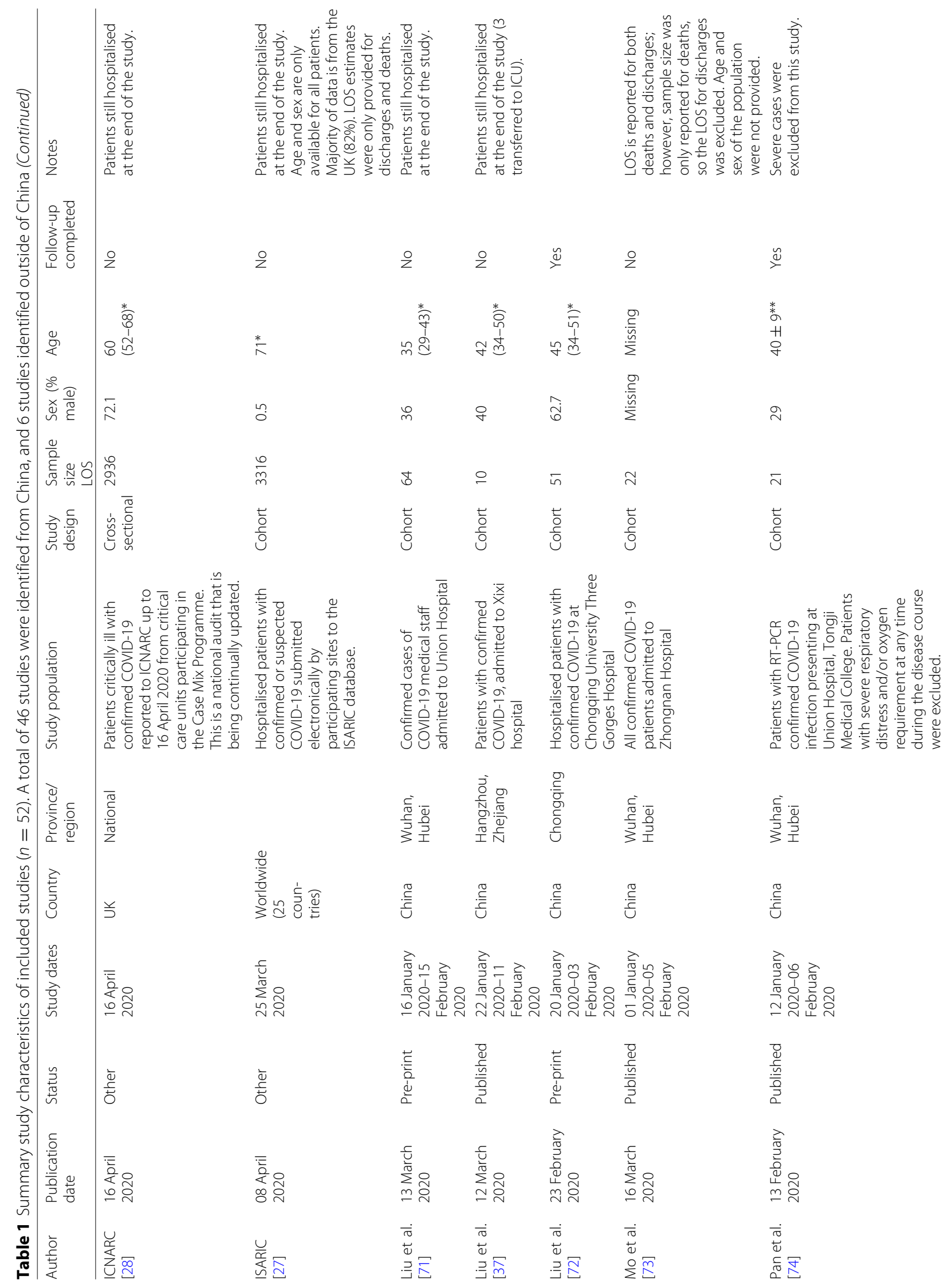




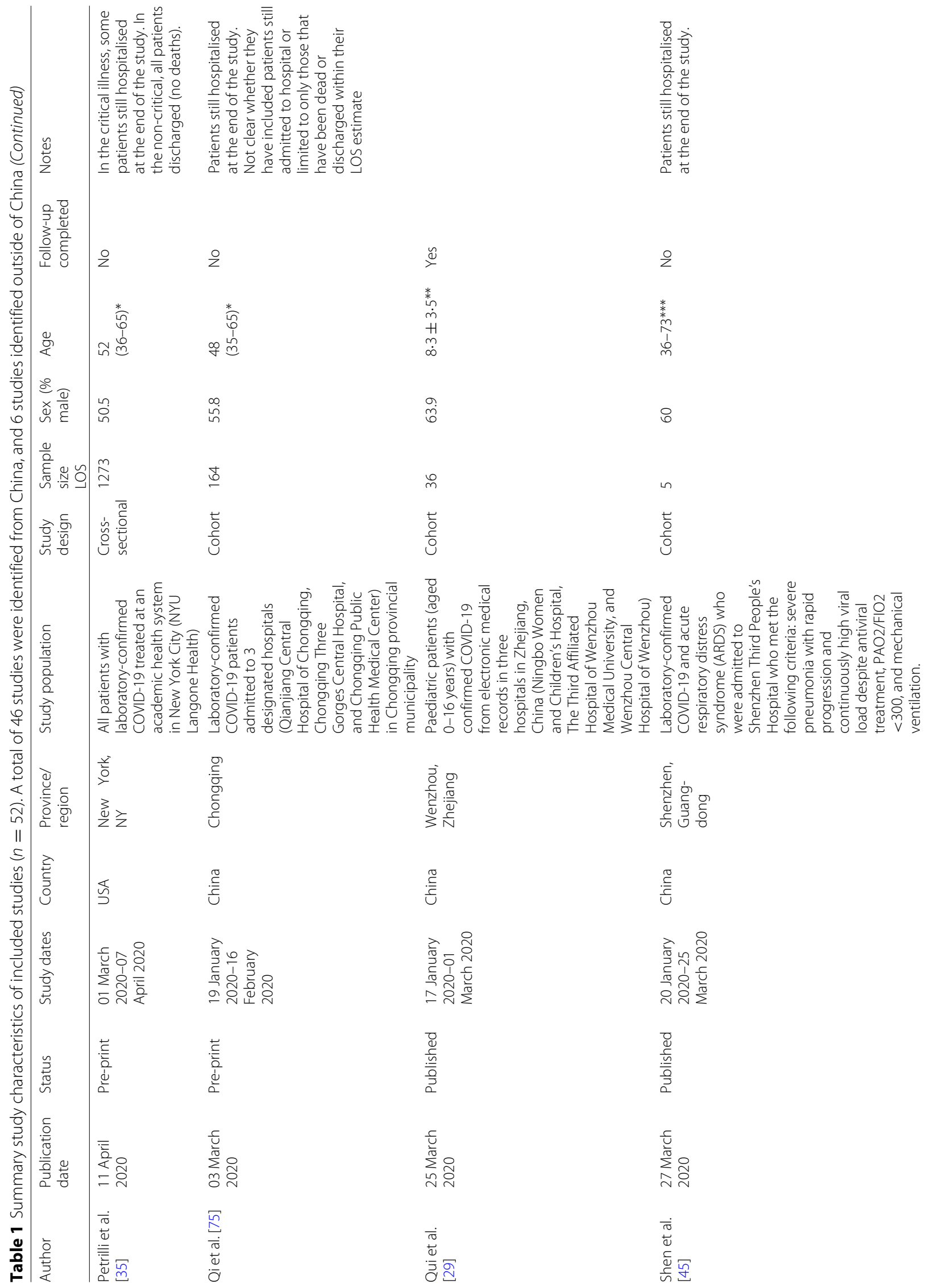




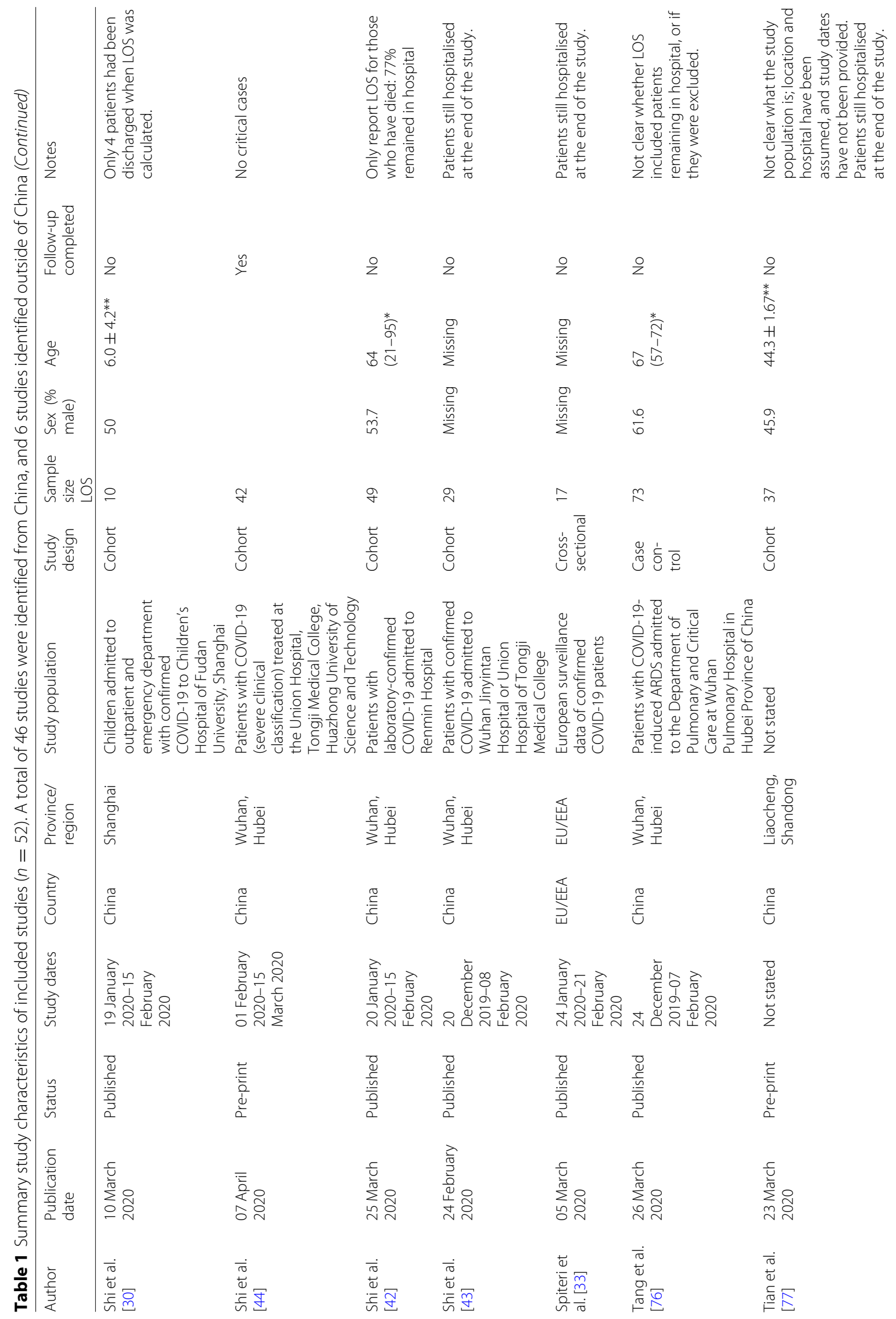




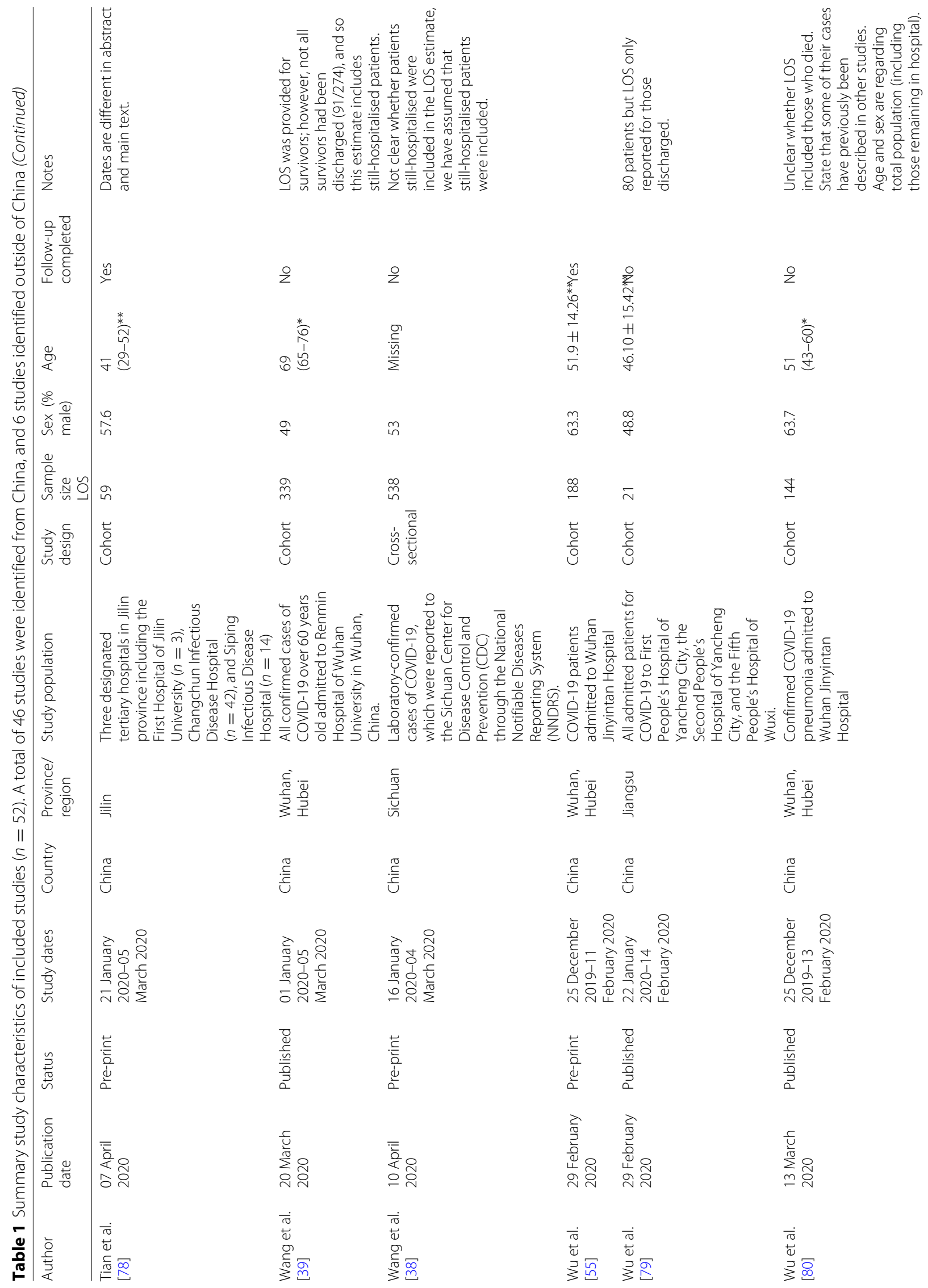




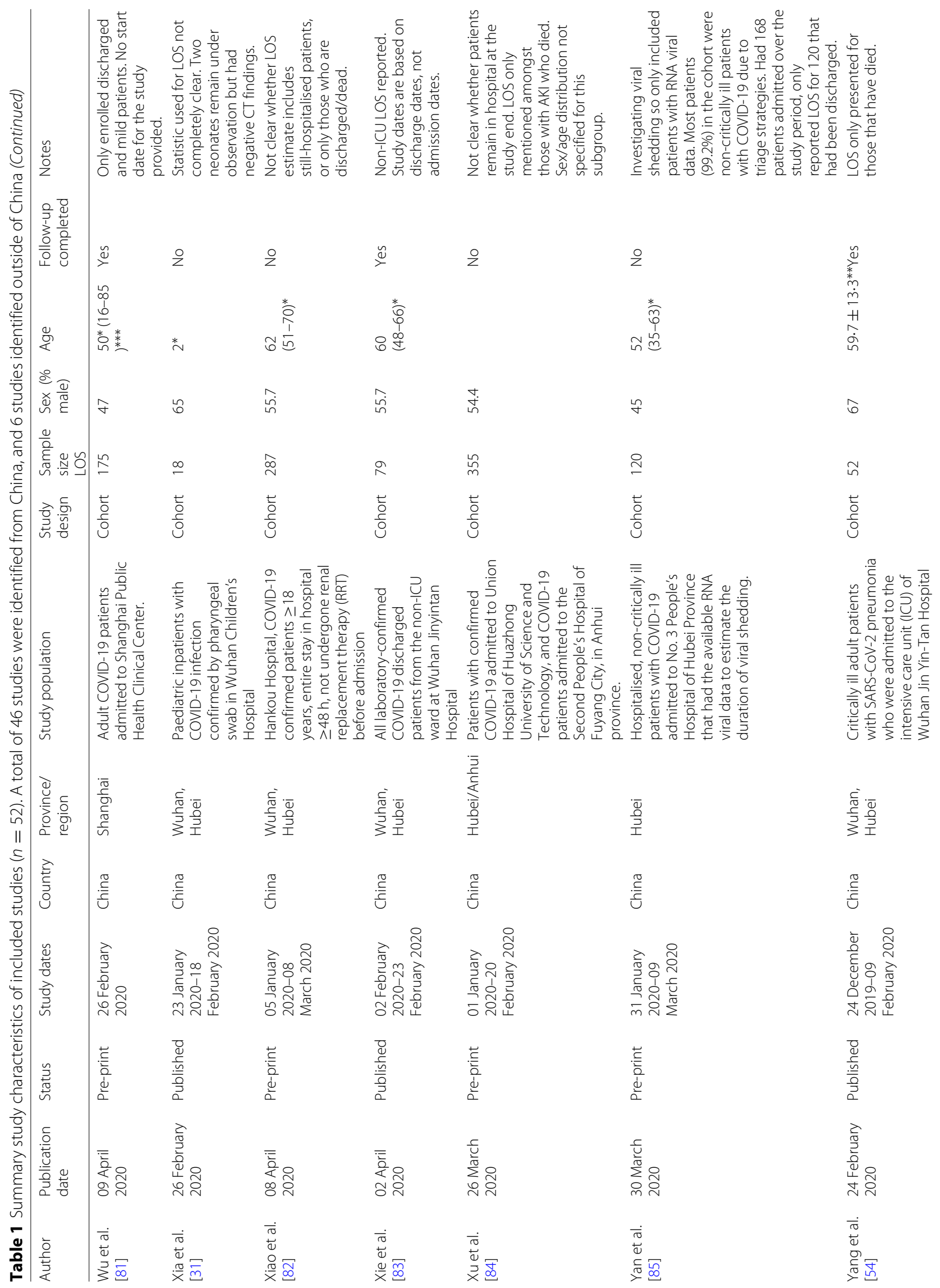




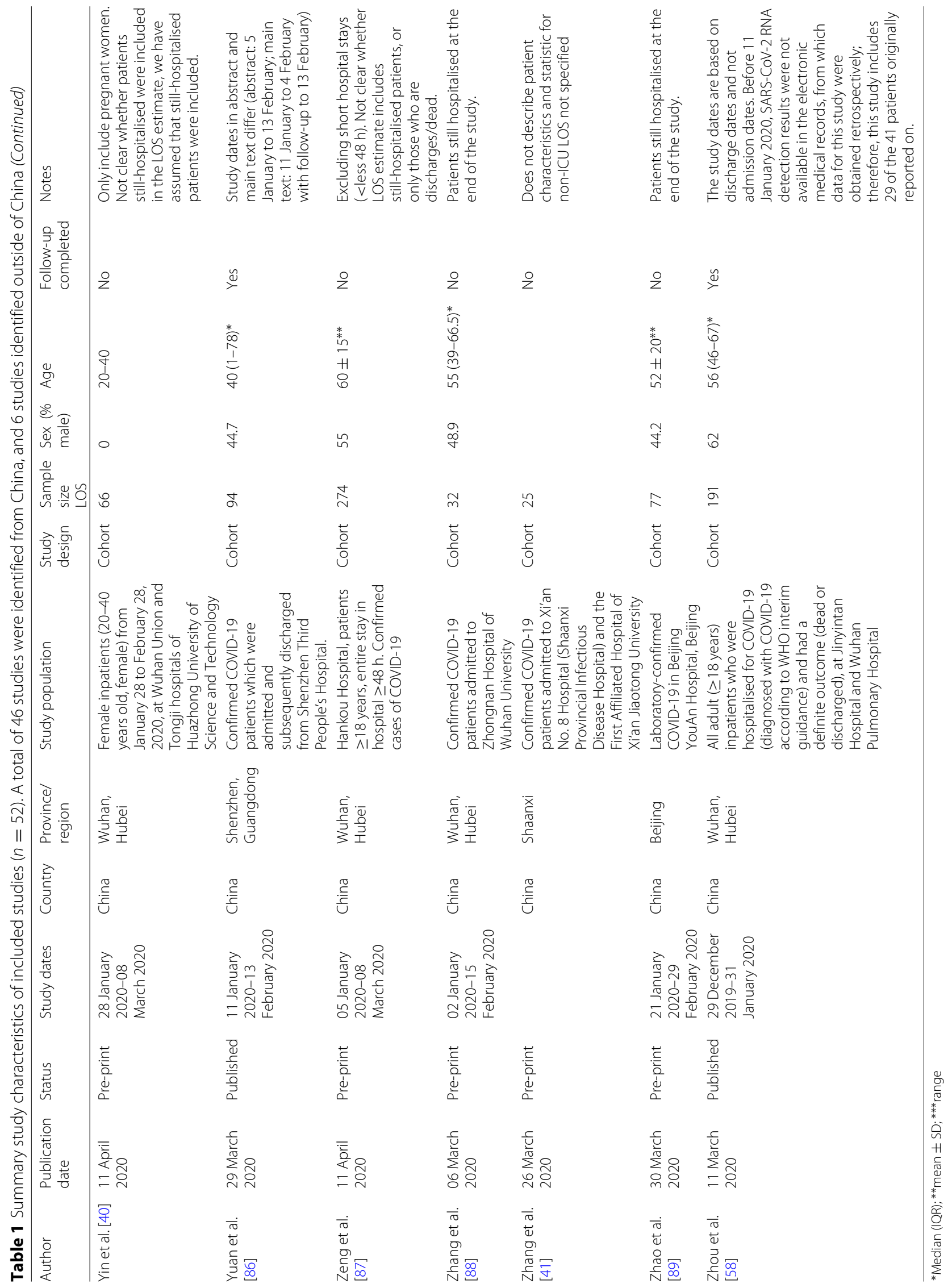


studies, weighted by sample size, 59 (9.6) years), and overall reported only a slightly higher proportion of males to females (54 (10.9) \% male). Three paediatric studies included patients from newborn to 18 years, with a weighted mean (SD) of 7 (2.8) years of age [29-31]. For the majority of studies, LoS was a secondary or incidental outcome rather than the primary outcome. As a result, age and sex distributions were not always specific to the LoS population, and instead reported for the overall study population. Furthermore, it was not always possible to accurately interpret the sample size of the population, nor whether the LoS estimate included still-hospitalised patients. All LoS data extracted from studies are reported in Supplementary Table B.

The majority of the included studies (46/52) were based in China, with a particularly high number reported from Wuhan (27/46), and many study populations were from the same outside of China: there was one study from Italy [32], one for the whole EU region [33], two from the USA $[34,35]$, one from the UK [28], and one study that collated LoS estimates from multiple countries excluding China (although the majority of the data are from the UK; [27]).

Most studies (43/52) reported LoS for total hospitalisation only, with four studies reporting LoS for ICU only, and five studies reporting both. Only 15 studies reported LoS for study populations with completed follow-up (patient discharge or death), with 37 reporting estimates for populations where some patients remained in hospital or in ICU. The majority of studies only included discharged or dead patients within their LoS estimate, even if they had incomplete follow-up of the full cohort. However, for 8 studies, it was unclear whether the reported LoS included patients who were still hospitalised [33, 34, 3641].

\section{Total hospital length of stay}

Estimates of the total hospital LoS are summarised in Fig. 2. Where provided, the overall study estimate of LoS for each discharge status is presented. For three studies, LoS was only reported within specific patient subgroups (relating to cardiac injury [42], COVID-19 recovery trajectory [43], and treatment comparison arms [44]); therefore, in these cases, we include both estimates. The longest stays were recorded in a study of five critically ill patients [45], of whom only three were discharged and all more than 50 days after admission, which does not appear representative of the overall distribution (see Fig. 2, Shen et al. (2020-01-20)). Excluding this study, the median duration of hospitalisation ranged from 5 to 29 days. There was no observed trend with respect to when the study was conducted (Fig. 2).

Estimates for LoS amongst patients who died in hospital were generally shorter than those for patients who were discharged alive, with medians between 4 and 21 days compared to 4 and 53 days, respectively. This difference is apparent in Fig. 2, where median LoS was lower for those discharged alive in 6 out of 8 studies that reported both outcomes. In studies that reported total hospital LoS by disease severity (11 studies, Supplementary Fig. A), there was a trend towards more severe cases having longer LoS. However, the definition of different levels of severity was inconsistent between studies so it is not possible to draw any confident conclusion.

Visual inspection of the study estimates suggested some evidence of a difference between total hospital LoS reported within and outside China, but studies outside China were too few (5/48) for a formal comparison. However, LoS reported within the ISARIC report [27] in particular (which includes contributed data from 25 countries, but with the majority of patients from the UK) gave a median and IQR (4 days (1-9)) substantially lower than the weighted mean from the studies from China (15.3 days).

The patient populations observed in these studies covered a wide range of ages, including three paediatric studies [29-31]. Amongst patients discharged alive, there appears to be little difference in average LoS between studies with the youngest and oldest patients, but the longest estimates came from studies with average age in the upper end of the range (Wang et al. [39] and Shi et al. [44], with average age of 68 and 69, respectively; Supplementary Fig. B). The LoS estimates which included nonsurvivors tended to come from studies with older populations, as is to be expected given the well-documented, age-dependent fatality rate [46].

\section{ICU length of stay}

Median stay in ICU ranged from 5 (IQR 2-9) to 19 (no IQR reported) days. There appeared to be less of a difference according to discharge status (alive or dead) than there was for total LoS (Fig. 3). A total of 8 studies reported ICU LoS estimates, with the same number of studies reporting LoS estimates from China and outside of China, and the resulting overall estimates are very similar. There were too few studies to conduct any comparison by age or disease severity.

\section{Estimated distributions}

Estimated summary hospital LoS distributions for studies from China and studies outside China are shown in Fig. 4. The median and IQR for total hospital was estimated to be $14(10-19)$ for China and 5 (3-9) excluding China. This was also repeated for ICU LoS, with a median and IQR 8 (5-13) for China and 7 (4-11) outside China. Comparing patient outcomes for total LoS, patients who died had a shorter LoS distribution (median, 8; IQR, 4-12) compared with patients who were discharged (median, 14; IQR, 11-17; Supplementary Fig. C). Studies from China 


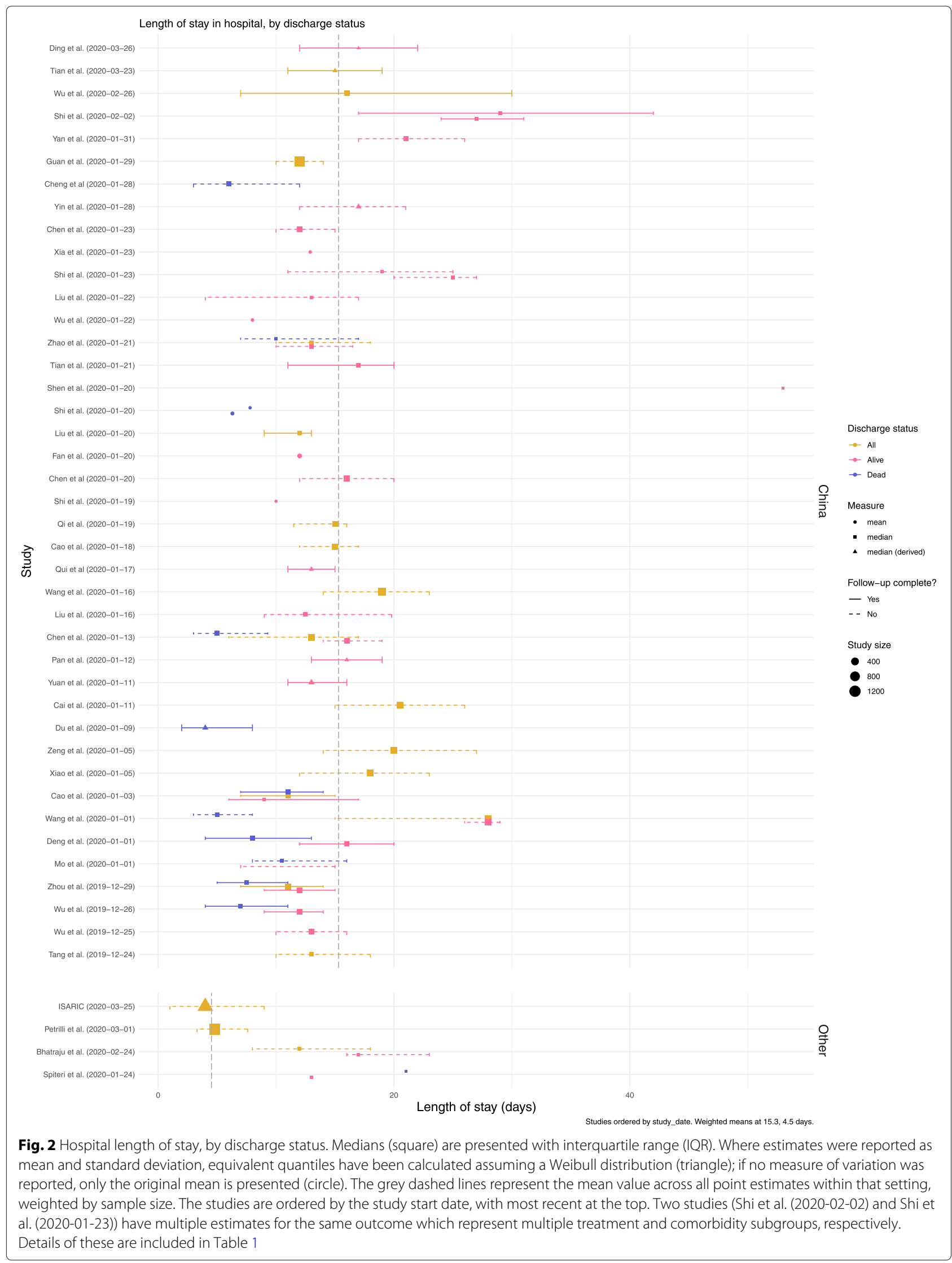




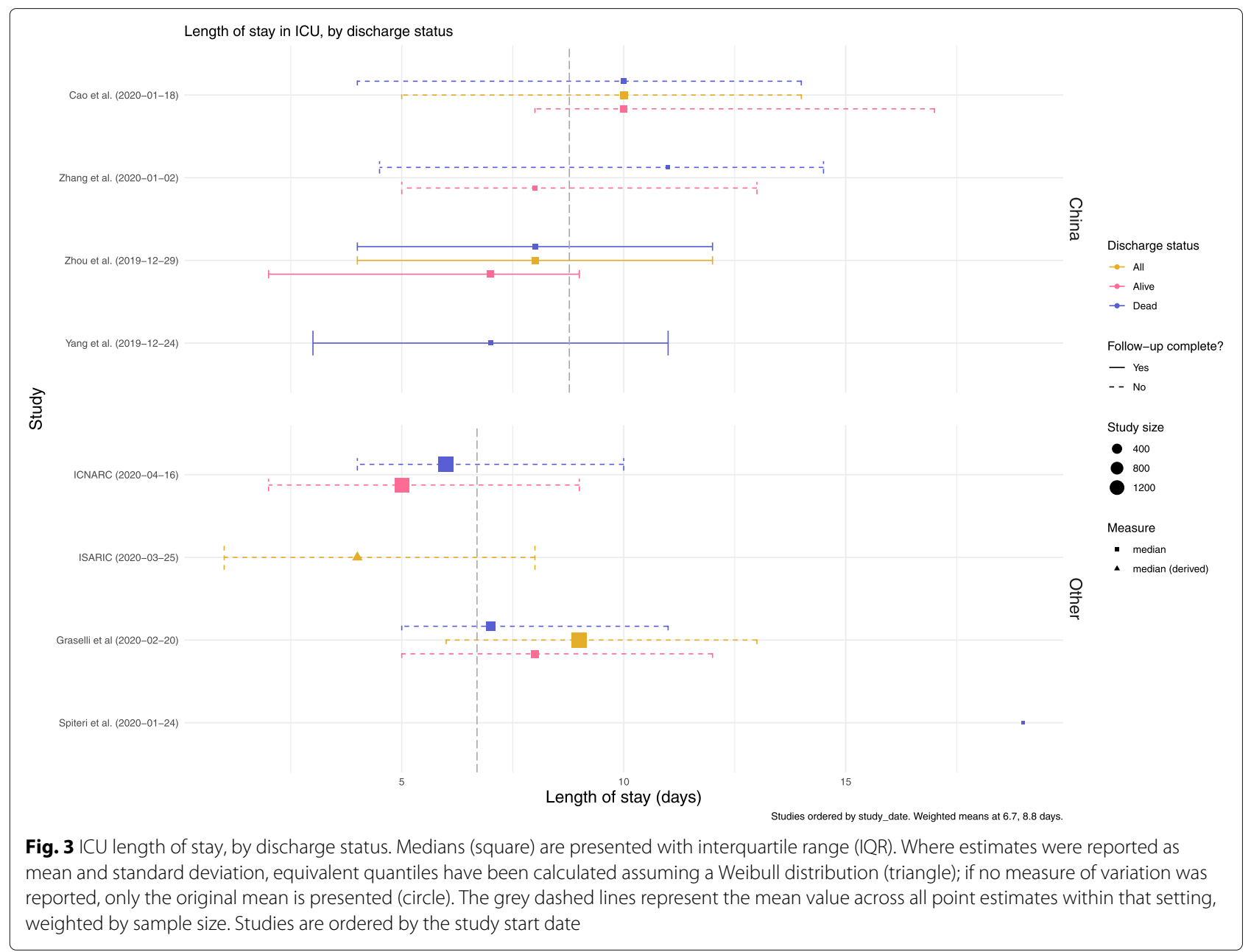

which had complete follow-up with respect to total hospital LoS were compared with studies with incomplete follow-up. A slight difference was observed, with shorter median LoS observed in studies with complete followup (median, 12; IQR, 8-17) compared with incomplete follow-up (median, 14; IQR, 10-19; Supplementary Fig. D). This was only performed for total hospital LoS in China, since no studies from outside China reported completed LoS for ICU. In addition, LoS estimates of all studies were compared with estimates where overlapping patient populations were removed (Supplementary Fig. E). A list of studies included in this analysis is presented in Supplementary table B. A small difference was observed, with longer LoS estimates observed in studies where overlapping populations had been removed $(n=17$; median, 16; IQR, 11-22) compared with estimates across all studies $(n=19$; median, 14 ; IQR, 10-19). Again, this sensitivity analysis was only performed for total hospital LoS in China, as it was the largest group.

For total hospital LoS in China, five studies were not included since they only provided point estimates for the
LoS. The point estimates from four of these studies fell within the IQR of the estimated distribution; however, for [45], the point estimate was much longer. For total LoS outside of China, one study reported only a point estimate [33], and this also fell outside of the estimated IQR. Sensitivity analysis showed that weighting by sample size had minimal influence on the shape of these distributions (Supplementary Fig. F).

\section{Discussion}

\section{Summary of findings}

Understanding how long patients hospitalised with COVID-19 remain in hospital is critical for planning and predicting bed occupancy as well as associated staff and equipment needs. This review found that hospital LoS observations for COVID-19 patients published in the literature to date varied from less than a week to nearly 2 months. Stay in intensive care was shorter and less variable, with studies reporting medians of 1 to 3 weeks. Where LoS was reported according to discharge status, stay was found to be shorter for those who died than 

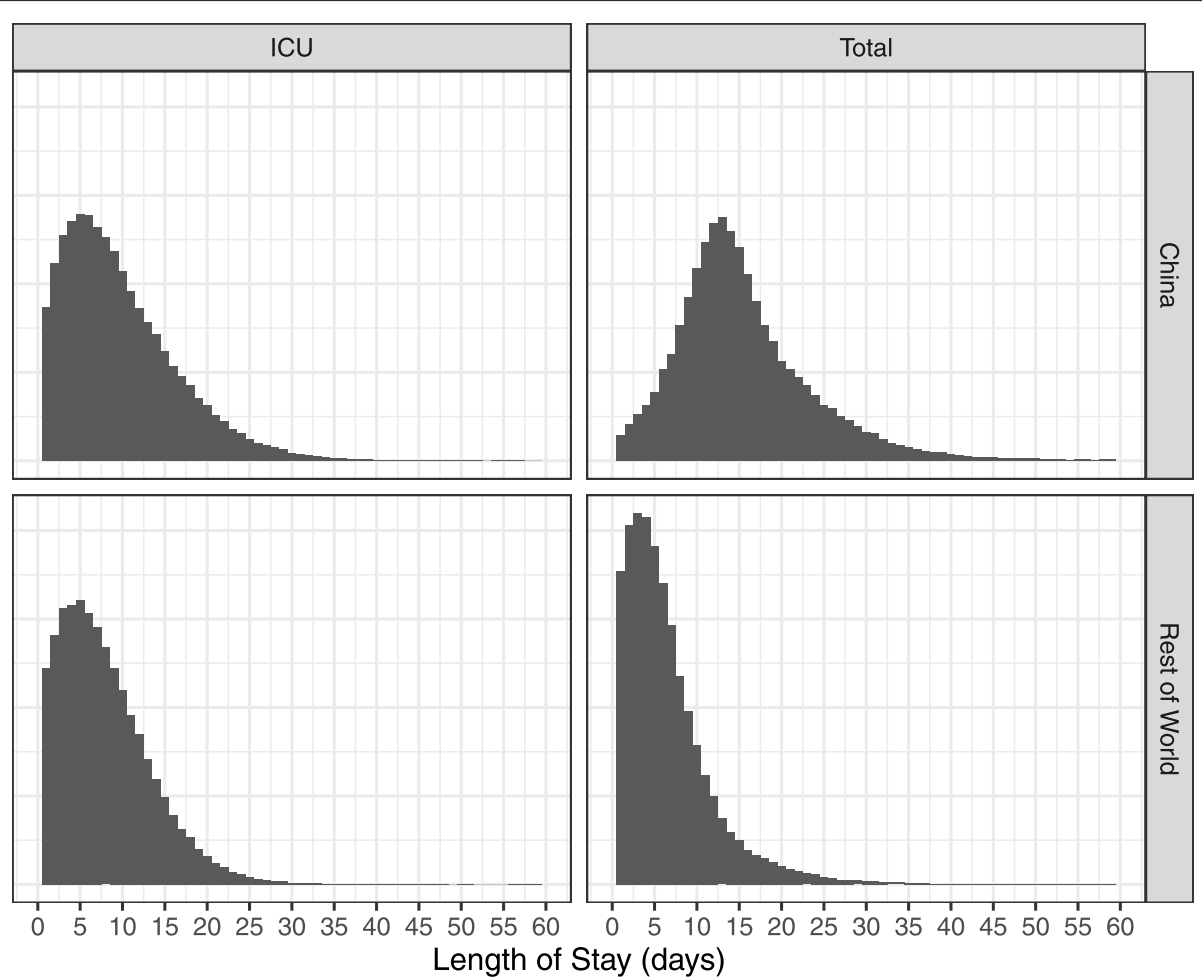

Fig. 4 Combined LOS distributions. Samples from the LoS distributions, split by location (China or rest of world) and type (ICU vs total LOS). For each subset, 100,000 draws were taken. The $x$-axis was cut at days $=60$

for those discharged alive; however, this difference was only apparent in terms of total stay and not stay in ICU (no statistical comparison was made). With respect to practical implications, knowledge of a difference between survivors and non-survivors is of less use since the outcome will not be known in advance in order to influence decision-making. To the authors' knowledge, this is the first formal review that has been conducted on hospital LoS for COVID-19.

The included studies yield some evidence of a difference between total hospital LoS observed in China and outside of China, with shorter LoS reported in the latter group (14 days (10-19) vs 5 days (3-9), respectively). However, only five studies were identified which reported LoS outside of China; therefore, this comparison is somewhat inconclusive. It may be that LoS is longer in China compared with other settings due to different criteria for hospital admission and discharge. A consensus exists across guidelines, such as ensuring resolution of symptoms and evidence of two negative PCR samples at least $24 \mathrm{~h}$ apart before discharge $[47,48]$; however, differences between settings may arise as a result of local capacity and strain on the health system. We attempted to capture this difference by recording time from onset of symptoms to admission; however, only one study outside of China reported this and a comparison was not possible. It is also possible that, with foresight from witnessing the Chinese epidemic, other countries set less strict criteria for discharge, in anticipation of stretched capacity. Other countries may also have used evidence from China to improve treatment methods and hence shorten LoS. However, this unfortunately appears unlikely as we did not observe a trend when looking at the reported LoS estimates over time.

In contrast, no difference was observed between settings for ICU LoS, for which there were an equal number of studies included from within and outside China. It is important to note that there might be key differences between ICUs in China compared with other countries, yet a definition for what constituted an ICU was rarely reported. Previous studies have found that ICU characteristics varied widely across geographic regions [49]. Further understanding of characteristics of ICUs reporting LoS for patients with COVID-19 is important in providing context on the reported estimates and should be investigated in future studies.

There appeared to be little difference of LoS observed by age in our results, apart from the fact that studies which reported deaths tended to have older patient populations. However, if there is indeed a trend, we were unlikely to observe strong evidence for it amongst these studies, since the majority include a similar mix of ages, often tending towards older cohorts, and the age distribution was 
not always provided for the specific subgroup who had LoS recorded. Two studies $[27,38]$ were included in the review which reported LoS by age, and they both found longer LoS associated with older age groups. In addition, two studies of LoS from the USA which were published after the search dates also reported a trend for longer LoS in older age groups [50,51]. Studies also reported LoS by disease severity; however, the definitions of disease severity were not consistent across studies, so we did not summarise by this.

\section{Limitations and biases}

Having been the first country to observe this novel coronavirus, published data on COVID-19 patient outcomes in China is more widely available than from countries to which the epidemic spread later on. The set of studies found in this review reflects this bias towards evidence obtained from China, particularly Wuhan. The small number of studies identified from outside of China means it is difficult to interpret comparisons across settings. Several studies have been published after our search dates which provide additional LoS estimates from outside of China. A study of 5700 patients from hospitals in the New York area reported comparable estimates for total LoS (median 4.5; IQR 2.4-8.1) [51]; however, studies from Northern Italy [52], Japan [53], and California and Washington [50] reported longer estimates of LoS. Therefore, the total LoS outside of China may in fact be longer than what we concluded. Our code is freely available on github, and additional studies may easily be added. As more studies emerge from a broader range of settings, it would be important to re-evaluate LoS estimates, as there are likely to be between-country differences that we have not captured here.

Furthermore, a number of studies include patients from the same hospital over the same period, for example, Yang et al. [54] and Wu et al. [55] who both reported patients from Jin Yin-Tan hospital in Wuhan, and it is possible that these studies had overlapping study populations. Furthermore, Guan et al. [36] was a national study conducted in China and ISARIC [27] included 25 countries worldwide; therefore, these studies may also include patients previously described. The effect of this double-counting would be to bias the overall summary statistics towards the LoS from these settings, and potentially reduce the total variation. Although this is acknowledged as an issue, it was not considered as a basis for exclusion since any criteria for selecting one study from the overlapping group would have been arbitrary and potentially induce another source of bias in itself. Therefore, we instead chose to conduct a sensitivity analysis based on a straightforward selection criteria of largest sample size from those studies with any potential for overlap, and found little difference between the estimates of LoS whether overlapping studies were included or excluded. The overall benefit of inclusion, particularly as many of these studies reported LoS for different subgroups, was deemed to outweigh the potential bias which may arise as a result of overlapping patient populations.

In this review, we were only able to distinguish between "total hospital LoS" and "ICU LoS", with many studies only reporting a total LoS. This total LoS will include both general hospital and ICU admissions within it. There is a need for more granularity with respect to patient pathways, distinguishing between admissions to different levels of care within one hospital episode in order to better inform healthcare contingencies. Patients may, for example, be transferred to ICU on more than one occasion during their stay, which is important to factor in when ICU capacity is particularly limited.

Changes in hospital demand may have also affected our estimates. At the beginning of the outbreak and in certain settings, hospitals were being used to isolate patients who were unable to isolate effectively at home [11, 12]. This means that LoS for patients in some of the earlier studies within this dataset could have been longer due to this logistical reason, rather than clinical need. Studies which mentioned this explicitly were excluded, yet there may still be others which were not so transparent. In addition, it is possible that, as hospitals reach the limits of their capacity, a more stringent triage policy may be implemented and the most critical patients may not be transferred to ICU. Despite this, we did not observe a trend when looking at the reported LoS estimates over time, suggesting that this is not in fact an important issue in our data.

Finally, many studies had incomplete follow-up with respect to LoS, and as a result, patients still hospitalised at the end of the study were not included in the summary statistics (right-truncation). This will bias estimates towards shorter LoS, as patients with longer LoS will not be included. A study by Lapidus et al. [56] investigated the bias associated with estimating average ICU LoS for COVID-19 patients based on observed LoS of discharged patients before follow-up of the entire patient cohort was completed. As expected, the authors found that the average LoS estimated at 3 months of follow-up was much longer than that estimated at 1 month. This potentially affects our estimates, given that 37 (out of 52) studies had incomplete follow-up with regard to LoS, although on comparison the difference between the groups was slight, and estimates where follow-up was complete were overall shorter. Several studies included still-hospitalised patients in their LoS summary without accounting for censoring $[33,34,36-41]$, which potentially alters interpretation of the values.

\section{Summarising length of stay}

We found that LoS is often not the primary measure of interest in studies which report it; however, it is an 
important parameter when it comes to forecasting bed occupancy during an outbreak. By conducting this review, we have systematically gathered a range of published estimates, providing a source from which researchers and decision-makers can obtain estimates specific to their population of interest (e.g. with respect to comorbidities) and allowing comparison of LoS between several different populations and settings.

There have been numerous previous studies which have aimed to forecast the number of hospital beds required for COVID-19 patients [16-22, 57]. Many of these studies published so far have used point estimates, only originating from one study which often does not reflect the context of interest. In particular, many used estimates from Zhou et al. [58] which reported a shorter total hospital LoS (median 11.0, IQR 7.0-14.0; Fig. 2), and a comparable ICU LoS (median 8.0, IQR 4.0-12.0; Fig. 3), compared with other studies from China. However, both of these were still longer than LoS estimates reported by studies outside of China. This means that the bed-forecasting studies relying on LoS estimates from Zhou et al. may be underestimating the number of beds required. This review has highlighted several potential sources of variation in LoS and identified common issues and biases which influence each individual estimate. This gives a motivation for considering a wider range of values than can be obtained in a single study, aiming instead to capture the overall distribution of LoS across a variety of possible patient trajectories.

Our findings provide both better estimates of the LoS distribution for patients hospitalised with COVID-19 and a method for generating these important distributions going forward. Combined with predictions of disease incidence, models forecasting bed occupancy are used to plan required hospital capacity and hence are critical for outbreak preparations. The LoS estimate is a critical parameter within such a model, and as such, any predictions are sensitive to the value or distribution being assumed, with strong implications for policy and planning. In particular, the tail of the LoS distribution must not be ignored since these few patients can block beds for a long time and form a heavy burden on capacity. Our estimates, and the proposed method for distribution collation, allow for improved predictions of this aspect of burden prediction and hence could reduce uncertainty in capacity preparedness in healthcare settings going forward. This is of value to countries still experiencing growing epidemics and those turning attention to the planning for the possibility of a second wave whilst restarting non-COVID care.

It is preferable to use data from the setting for which you are trying to forecast bed occupancy (as was done by the IHME COVID-19 health service utilisation forecasting team [15]); however, data on completed patient stays will often not be available until well after the onset of the epidemic. Furthermore, LMICs may have reduced capacity for surveillance and monitoring in order to obtain these data. In such cases, where countries are in the early stages of an outbreak, it would be better to use a conservative (i.e. broad) distribution of LoS from another setting. As the pandemic progresses and more countries observe patients completing their hospital episodes, it will be possible to add further setting-specific summaries and improve this distribution.

As far as the authors are aware, the approach demonstrated here to summarise median and IQRs across multiple studies has not been proposed before, although there are similarities with the approach taken by others in the CMMID Working Group to pool $R_{0}$ estimates [59]. We present an intuitive method which exploits two optimisation methods to fit parametric distributions based on reported summary statistics rather than individual data, then samples across them. In this way, we capture the central tendency and overall variation between a set of quantiles from different study populations. This allows multiple sources of evidence to be consolidated into a single distribution which can be used in bed forecasting going forward. By providing both the code for this analysis and our summary distributions, better bed occupancy predictions can be made in the future.

\section{Conclusion}

This review summarised the available literature to provide estimates of LoS for total hospital admission and ICU which can be applied for planning and preparedness for SARS-CoV-2. We found substantial differences between China and other settings in terms of total hospital stay, but little evidence for an impact on LoS of time of study, age, or disease severity. We present summary distributions which can be used within models making predictions about bed requirements, and suggest that this may be a more robust and realistic way to characterise LoS than relying on summary data from just one setting or hospital. The majority of the data presented in this review comes from China, and as more data become available, it will be important to update this with setting-specific LoS estimates. Understanding the duration of hospitalisation of COVID-19 patients is critical for providing insights as to when hospitals will reach capacity, as well predicting associated staff or equipment requirements.

\section{Supplementary information}

Supplementary information accompanies this paper at https://doi.org/10.1186/s12916-020-01726-3.

Additional file 1: List of search terms. Supplementary Table A. Description of information extracted from included studies. Fig SA: LoS by 
disease severity. Fig SB: LoS by study median age. Fig SC: LoS by outcome status. Fig SD: Summary distributions for China/other and total/ICU. Fig SE: Sensitivity of length of stay (LOS) with and without overlapping populations removed. Fig SF: Sensitivity analysis of summary distributions to weighting.

Additional file 2: Supplementary Table B. Database of all studies included within the review. Available as an excel spreadsheet.

\section{Abbreviations}

LoS: Length of stay; ICU: Intensive care unit; IQR: Interquartile range; SD: standard deviation; LMIC: low- and middle-income country; PRISMA: Preferred Reporting Items for Systematic Reviews; RCT: randomised control trial.

\section{Acknowledgements}

The authors gratefully acknowledge funding of the SPEAK India Consortium by the Bill and Melinda Gates Foundation (OPP1 183986) for publication of this work.

We would also like to acknowledge the other members of the London School of Hygiene and Tropical Medicine COVID-19 modelling group, within the Centre for Mathematical Modelling of Infectious Diseases (CMMID working group), who contributed to this work: Rosalind M Eggo (HDR UK: MR/S003975/1, UK MRC: MC_PC 19065), Megan Auzenbergs (BMGF: OPP1191821), Billy J Quilty (NIHR: 16/137/109), Nicholas G. Davies (NIHR: Health Protection Research Unit for Modelling Methodology HPRU-2012-10096), Mark Jit (BMGF: INV-003174, NIHR: 16/137/109, European Commission: 101003688), Jon C Emery (ERC Starting Grant: 757699), Petra Klepac (Royal Society: RP/EA/180004, European Commission: 101003688), Sam Abbott (Wellcome Trust: 210758/Z/18/Z), Sophie R Meakin (Wellcome Trust: 210758/Z/18/Z), Anna M Foss, Fiona Yueqian Sun (NIHR: 16/137/109), Stéphane Hué, Kathleen O'Reilly (BMGF: OPP1191821), Amy Gimma (Global Challenges Research Fund: ES/P010873/1), Adam J Kucharski (Wellcome Trust: 206250/Z/17/Z), Kiesha Prem (BMGF: INV-003174, European Commission: 101003688), Christopher I Jarvis (Global Challenges Research Fund: ES/P010873/1), Damien C Tully, Sebastian Funk (Wellcome Trust: 210758/Z/18/Z), David Simons (BBSRC LIDP. BB/M009513/1), Arminder K Deol, Alicia Rosello (NIHR: PR-OD-1017-20002), W John Edmunds (European Commission: 101003688), Joel Hellewell (Wellcome Trust: 210758/Z/18/Z), Timothy W Russell (Wellcome Trust: 206250/Z/17/Z), Graham Medley (BMGF: NTD Modelling Consortium OPP1184344), C Julian Villabona-Arenas, Kevin van Zandvoort (Elrha R2HC/UK DFID/Wellcome Trust/NIHR, DFID/Wellcome Trust: Epidemic Preparedness Coronavirus research programme 221303/Z/20/Z), Katherine E. Atkins, Quentin J Leclerc (UK MRC: LID DTP MR/N013638/1), Nikos I Bosse (Wellcome Trust: 210758/Z/18/Z), Yang Liu (BMGF: INV-003174, NIHR: 16/137/109, European Commission: 101003688), Akira Endo (Nakajima Foundation, Alan Turing Institute), Hamish P Gibbs (UK DHSC/UK Aid/NIHR: ITCRZ 03010), Charlie Diamond (NIHR: 16/137/109), Rachel Lowe (Royal Society: Dorothy Hodgkin Fellowship), Stefan Flasche (Wellcome Trust: 208812/Z/17/Z), Rein M G J Houben (ERC Starting Grant: 757699), and James D Munday (Wellcome Trust: 210758/Z/18/Z).

\section{Authors' contributions}

EMR: conceptualisation, methodology, literature search, literature screening, data extraction, data analysis, visualisation, interpretation, and writing original draft. ESN: methodology, literature search, literature screening, data extraction, data analysis, visualisation, interpretation, and writing —original draft. YJ: literature screening, data extraction, interpretation, and writing - review and editing. NRW: methodology, data analysis, visualisation, and writing —-review and editing. SC: methodology and writing—review and editing. CABP: code review and writing — review and editing. CMMID Working Group: each contributed in processing, cleaning, and interpretation of data; interpreted findings; contributed to the manuscript; and approved the work for publication. TJ: methodology, code review, and writing - review and editing. GMK: conceptualisation, methodology, interpretation, and writing - review and editing. SRP: conceptualisation, methodology, literature screening, data extraction, interpretation, and writing — review and editing. Al authors read and approved the final manuscript.

\section{Funding}

EMR receives funding from the Medical Research Council London Intercollegiate Doctoral Training Program (MR/N013638/1). ESN receives funding from the Bill and Melinda Gates Foundation via the SPEAK India Consortium (OPP1183986). YJ receives funding from LSHTM. NRW receives funding from the UK Medical Research Council (MR/N013638/1). SC receives funding from the Wellcome Trust (208812/Z/17/Z). CABP receives funding from Bill and Melinda Gates Foundation NTD Modelling Consortium OPP1 184344 and DFID/Wellcome Trust: Epidemic Preparedness Coronavirus research programme 221303/Z/20/Z. TJ receives funding from the UK Public Health Rapid Support Team, NIHR Health Protection Research Unit for Modelling Methodology (HPRU-2012-10096), and the UK Economic and Social Rsearch Council (ES/P010873/1). SRP receives funding from the Bill and Melinda Gates Foundation (OPP1180644). GMK receives funding from the UK Medical Research Council (MR/P014658/1).

\section{Availability of data and materials}

The data and code used in this work can be accessed at https://github.com/ esnightingale/los_review.

\section{Ethics approval and consent to participate} Not applicable.

\section{Consent for publication}

Not applicable.

\section{Competing interests}

The authors declare that they have no competing interests.

\section{Author details}

${ }^{1}$ Department of Infectious Disease Epidemiology, London School of Hygiene and Tropical Medicine, Keppel Street, London, UK. ${ }^{2}$ Department of Global Health and Development, London School of Hygiene and Tropical Medicine, Keppel Street, London, UK. ${ }^{3}$ South African DSI-NRF Centre of Excellence in Epidemiological Modelling and Analysis (SACEMA), Stellenbosch University, Stellenbosch, Republic of South Africa. ${ }^{4}$ UK Public Health Rapid Support Team, London, UK. ${ }^{5}$ MRC Centre for Global Infectious Disease Analysis, Department of Infectious Disease Epidemiology, School of Public Health, Imperial College, London, UK

Received: 30 April 2020 Accepted: 30 July 2020

Published online: 03 September 2020

\section{References}

1. World Health Organization. 2020. Coronavirus disease 2019 (COVID-19) situation report, 95, Geneva. Available from: https://www.who.int/docs/ defaultsource/coronaviruse/situation-reports/20200424-sitrep-95-covid19.pdf?sfvrsn=e8065831_4.

2. Xie J, Tong Z, Guan X, Du B, Qiu H, Slutsky AS. Critical care crisis and some recommendations during the COVID-19 epidemic in China. Intensive Care Med. 2020;46:837-40. Available from: https://doi.org/10. 1007/s00134-020-05979-7.

3. Qiu H, Tong Z, Ma P, Hu M, Peng Z, Wu W, Du B. Intensive care during the coronavirus epidemic. Intensive Care Med. 2020:46(4):576-8. Available from: https://doi.org/10.1007/s00134-020-05966-y.

4. Remuzzi A, Remuzzi G. COVID-19 and Italy: what next? Lancet. 2020;395(10231):1225-8. Available from: https://www.thelancet.com/ journals/lancet/article/PIIS0140-6736(20)3062\%7-9/abstract.

5. Paterlini M. On the front lines of coronavirus: the Italian response to covid-19. BMJ. 2020;368:m1065. Available from: https://www.bmj.com/ content/368/bmi.m1065.

6. Legido-Quigley H, Mateos-Garciá JT, Campos VR, Gea-Sánchez M, Muntaner C, McKee M. The resilience of the Spanish health system against the COVID-19 pandemic. Lancet Public Health. 2020;5(5):251-2. Available from: https://www.thelancet.com/journals/lanpub/article/ PIIS2468-2667(20)3006\%0-8/abstract.

7. Rosenbaum L. Facing Covid-19 in Italy?ethics, logistics, and therapeutics on the epidemic's front line. N Engl J Med. 2020;382(20):1873-5. Available from: https://doi.org/10.1056/NEJMp2005492.

8. Rodriguez-Morales AJ, Cardona-Ospina JA, Gutiérrez-Ocampo E, Villamizar-Peña R, Holguin-Rivera Y, Escalera-Antezana JP, AlvaradoArnez LE, Bonilla-Aldana DK, Franco-Paredes C, Henao-Martinez AF, et al. Clinical, laboratory and imaging features of COVID-19: a systematic review and meta-analysis. Travel Med Infect Dis. 2020101623. Available from: http://www.sciencedirect.com/science/article/pii/S1477893920300910. 
9. Cascella M, Rajnik M, Cuomo A, Dulebohn SC, Di Napoli R. Features, evaluation and treatment coronavirus (COVID-19). In: StatPearls. Treasure Island (FL). StatPearls Publishing; 2020. Available from: http://www.ncbi. nlm.nih.gov/books/NBK554776/.

10. Jiang F, Deng L, Zhang L, Cai Y, Cheung CW, Xia Z. Review of the clinical characteristics of coronavirus disease 2019 (COVID-19). J Gen Intern Med. 20201-5. Available from: https://doi.org/10.1007/s11606-020-05762-w.

11. Chen S, Zhang Z, Yang J, Wang J, Zhai X, Bärnighausen T, Wang C. Fangcang shelter hospitals: a novel concept for responding to public health emergencies. Lancet. 2020;395(10232):1305-14. Available from: https://www.thelancet.com/journals/lancet/article/PIIS01406736(20)30744-3.

12. Wu Z, McGoogan JM. Characteristics of and important lessons from the coronavirus disease 2019 (COVID-19) outbreak in China: summary of a report of 72314 cases from the Chinese Center for Disease Control and Prevention. JAMA. 2020;323(13):1239-42. Available from: https:// jamanetwork.com/journals/jama/fullarticle/2762130.

13. Yang J, Zheng Y, Gou X, Pu K, Chen Z, Guo Q, Ji R, Wang H, Wang Y, Zhou Y. Prevalence of comorbidities and its effects in coronavirus disease 2019 patients: a systematic review and meta-analysis. Int J Infect Dis. 2020;94:91-5. Available from: http://www.sciencedirect.com/science/ article/pii/S1201971220301363.

14. Clark A, Jit M, Warren-Gash C, Guthrie B, Wang HH, Mercer SW, Sanderson C, McKee M, Troeger C, Ong Kl, et al. How many are at increased risk of severe COVID-19 disease? Rapid global, regional and national estimates for 2020. medRxiv. 2020. Available from: https://www. medrxiv.org/content/10.1101/2020.04.18.20064774.

15. COVID IHME, Murray CJ. Forecasting COVID-19 impact on hospital bed-days, ICU-days, ventilator-days and deaths by US state in the next 4 months. Infect Dis (except HIV/AIDS). 2020. Available from: http:// medrxiv.org/lookup/doi/10.1101/2020.03.27.20043752.

16. Deasy J, Rocheteau E, Kohler K, Stubbs DJ, Barbiero P, Liò P, Ercole A Forecasting ultra-early intensive care strain from COVID-19 in England. medRxiv. 2020. Available from: http://medrxiv.org/content/early/2020/ 04/07/2020.03.19.20039057

17. Ferstad JO, Gu AJ, Lee RY, Thapa I, Shin AY, Salomon JA, Glynn P, Shah $\mathrm{NH}$, Milstein A, Schulman K, Scheinker D. A model to forecast regional demand for COVID-19 related hospital beds. medRxiv. 2020. Available from: http://medrxiv.org/content/early/2020/04/07/2020.03.26.20044842.

18. Weissman GE, Crane-Droesch A, Chivers C, Luong T, Hanish A, Levy MZ, Lubken J, Becker M, Draugelis ME, Anesi GL, et al. Locally informed simulation to predict hospital capacity needs during the COVID-19 pandemic. Ann Intern Med. 2020;173(1):21-8. Available from: https://doi. org/10.7326/M20-1260.

19. Massonnaud C, Roux J, Crépey P. COVID-19: forecasting short term hospital needs in France. medRxiv. 2020. Available from: http://medrxiv. org/content/early/2020/03/20/2020.03.16.20036939.

20. Moghadas SM, Shoukat A, Fitzpatrick MC, Wells CR, Sah P, Pandey A Sachs JD, Wang Z, Meyers LA, Singer BH, et al. Projecting hospital utilization during the COVID-19 outbreaks in the United States. Proc Natl Acad Sci. 2020;117(16):9122-6. Available from: https://www.pnas.org/ content/117/16/9122

21. Shoukat A, Wells CR, Langley JM, Singer BH, Galvani AP, Moghadas SM. Projecting demand for critical care beds during COVID-19 outbreaks in Canada. CMAJ. 2020;192(19):489-96. Available from: https://www.cmaj. ca/content/early/2020/04/09/cmaj.200457.

22. Castro MC, Carvalho LR, Chin T, Kahn R, Franca GVA, Macario EM, de Oliveira WK. Demand for hospitalization services for COVID-19 patients in Brazil. medRxiv. 2020. Available from: https://www.medrxiv.org/content/ 10.1101/2020.03.30.20047662.

23. Marazzi A, Paccaud F, Ruffieux C, Beguin C. Fitting the distributions of length of stay by parametric models. Med Care. 1998;36(6):915-27.

24. R Core Team. R stats package version 1.14.4. Available from: https://www. rdocumentation.org/packages/stats/versions/3.6.2

25. Macdonald P, Du J. 2018. Mixdist: finite mixture distribution models version 0.5-5. Available from: https://CRAN.R-project.org/package= mixdist.

26. Locke S, FitzJohn R, Cori A, Jombart T. distcrete: Discrete Distribution Approximations version 1.0.3. 2017. Available from: https://CRAN. Rproject.org/package=distcrete.

27. International Severe Acute Respiratory and Emerging Infections Consortium (ISARIC). 2020. COVID-19 report. Available from: https://
media.tghn.org/medialibrary/2020/04/ISARIC_Data_Platform_COVID\%19_Report_8APR20.pdf.

28. Intensive Care National Audit and research Centre (ICNArC). 2020. Report on 2249 patients critically ill with COVID-19. Available from: https://www. icnarc.org/Our-AuditLatest-News2020/04/04/report-On-2249-PatientsCritically-III-With-Covid-19.

29. Qiu H, Wu J, Hong L, Luo Y, Song Q, Chen D. Clinical and epidemiological features of 36 children with coronavirus disease 2019 (COVID-19) in Zhejiang, China: an observational cohort study. Lancet Infect Dis. 2020;20(6):689-96. Available from: https://www.thelancet.com/ journals/laninf/article/PIIS1473-3099(20)3019\%8-5.

30. Shi Y, Wang $X$, Liu G, Zhu Q, Wang J, Yu H, Wang C, Wang L, Zhang M, Zhang $L$, et al. A quickly, effectively screening process of novel corona virus disease 2019 (COVID-19) in children in Shanghai, China. Ann Trans Med. 2020;8(5):241. Available from: http://atm.amegroups.com/article/ view/37468.

31. Xia W, Shao J, Guo Y, Peng X, Li Z, Hu D. Clinical and CT features in pediatric patients with COVID-19 infection: different points from adults. Pediatr Pulmonol. 2020;55(5):1169-74. Available from: https:// onlinelibrary.wiley.com/doi/abs/10.1002/ppul.24718.

32. Grasselli G, Zangrillo A, Zanella A, Antonelli M, Cabrini L, Castelli A, Cereda D, Coluccello A, Foti G, Fumagalli R, et al. Baseline characteristics and outcomes of 1591 patients infected with SARS-CoV-2 admitted to ICUs of the Lombardy Region, Italy. JAMA. 2020;323(16):1574-81. Available from: https://doi.org/10.1001/jama.2020.5394.

33. Spiteri G, Fielding J, Diercke M, Campese C, Enouf V, Gaymard A, Bella A, Sognamiglio P, Moros MJS, Riutort AN, et al. First cases of coronavirus disease 2019 (COVID-19) in the WHO European Region, 24 January to 21 February 2020. Eurosurveillance. 2020;25(9):2000178. Available from: https://www.eurosurveillance.org/content/10.2807/1560-7917.ES.2020. 25.9.2000178.

34. Bhatraju PK, Ghassemieh BJ, Nichols M, Kim R, Jerome KR, Nalla AK Greninger AL, Pipavath S, Wurfel MM, Evans L, et al. Covid-19 in critically ill patients in the Seattle region?case series. N Engl J Med. 2020;382(21): 2012-22. Available from: https://www.nejm.org/doi/full/10.1056/ NEJMoa2004500.

35. Petrilli CM, Jones SA, Yang J, Rajagopalan H, O'Donnell LF, Chernyak Y, Tobin K, Cerfolio RJ, Francois F, Horwitz LI. Factors associated with hospitalization and critical illness among 4,103 patients with COVID-19 disease in New York City. medRxiv. 2020. Available from: http://medrxiv. org/content/early/2020/04/11/2020.04.08.20057794.

36. Guan Wj, Ni Zy, Hu Y, Liang Wh, Ou Cq, He Jx, et al. Clinical characteristics of coronavirus disease 2019 in China. N Engl J Med. 2020. Massachusetts Medical Society. Available from: https://doi.org/10.1056/NEJMoa2002032.

37. Liu F, Xu A, Zhang Y, Xuan W, Yan T, Pan K, et al. Patients of COVID-19 may benefit from sustained lopinavir-combined regimen and the increase of eosinophil may predict the outcome of COVID-19 progression. Int J Infect Dis. 2020S1201971220301326. Available from: https://linkinghub.elsevier.com/retrieve/pii/S1201971220301326.

38. Wang Z, Ji JS, Liu Y, Liu R, Zha Y, Chang X, et al. Survival analysis of hospital length of stay of novel coronavirus (COVID-19) pneumonia patients in Sichuan, China. medRxiv. 2020. Available fromhttp://medrxiv. org/content/early/2020/04/10/2020.04.07.20057299.abstract.

39. Wang L, He W, Yu X, Hu D, Bao M, Liu H, et al. Coronavirus disease 2019 in elderly patients: characteristics and prognostic factors based on 4-week follow-up. J Infect. 2020;80:639-45.

40. Yin M, Zhang L, Deng G, Han C, Shen M, Sun H, et al. Severe acute respiratory syndrome coronavirus 2 (SARS-CoV-2) infection during pregnancy in China: a retrospective cohort study. medRxiv. 2020. Available from: http://medrxiv.org/content/early/2020/04/11/2020.04.07. 20053744.abstract.

41. Zhang D, Guo R, Lei L, Liu H, Wang Y, Wang Y, et al. COVID-19 infection induces readily detectable morphological and inflammation-related phenotypic changes in peripheral blood monocytes, the severity of which correlate with patient outcome. medRxiv. 2020. Available fromhttp:// medrxiv.org/content/early/2020/03/26/2020.03.24.20042655.abstract.

42. Shi S, Qin M, Shen B, Cai Y, Liu T, Yang F, et al. Association of cardiac injury with mortality in hospitalized patients with COVID-19 in Wuhan, China. JAMA Cardiol. 2020;5:802-10.

43. Shi H, Han X, Jiang N, Cao Y, Alwalid O, Gu J, et al. Radiological findings from 81 patients with COVID-19 pneumonia in Wuhan, China: a 
descriptive study. Lancet Infect Dis. 2020;20(4):425-34. Available from: https://www.unboundmedicine.com/medline/citation/32105637/ Radiological_findings_from_81_patients_with_COVID_19_pneumonia_ in_Wuhan_China:_a_descriptive_study_.

44. Shi C, Wang C, Wang H, Yang C, Cai F, Zeng F, et al. The potential of low molecular weight heparin to mitigate cytokine storm in severe COVID-19 patients: a retrospective clinical study. medRxiv. 2020. Available from: http://medrxiv.org/content/early/2020/04/15/2020.03.28.20046144. abstract.

45. Shen C, Wang Z, Zhao F, Yang Y, Li J, Yuan J, et al. Treatment of 5 critically ill patients with COVID-19 with convalescent plasma. JAMA 2020. Available from: https://doi.org/10.1001/jama.2020.4783.

46. CDC. Coronavirus disease 2019 (COVID-19). 2020. Available from: https:// www.cdc.gov/coronavirus/2019-ncov/need-extra-precautions/peopleat-higher-risk.html.

47. for Disease PreventionandControl EC. Discharge criteria for confirmed COVID-19 cases. 2020. Available from: https://www.ecdc.europa.eu/sites/ default/files/documents/COVID-19-Discharge-criteria.pdf.

48. Commission CNH. COVID-19 diagnostic guidelines (version 3). 2020. Available from: http://www.chinacdc.cn/jkzt/crb/zl/szkb_11803/ jszl_11815/202001/W020200123581113562555.pdf.

49. Sakr Y, Moreira CL, Rhodes A, Ferguson ND, Kleinpell R, Pickkers P, et al. The impact of hospital and ICU organizational factors on outcome in critically ill patients: results from the extended prevalence of infection in intensive care study*. Crit Care Med. 2015;43(3):519-26. Available fromhttp://journals.lww.com/00003246-201503000-00002.

50. Lewnard JA, Liu VX, Jackson ML, Schmidt MA, Jewell BL, Flores JP, et al. Incidence, clinical outcomes, and transmission dynamics of hospitalized 2019 coronavirus disease among 9,596,321 individuals residing in California and Washington, United States: a prospective cohort study. Epidemiology. 2020. Available from: http://medrxiv.org/lookup/doi/10. 1101/2020.04.12.20062943.

51. Richardson S, Hirsch JS, Narasimhan M, Crawford JM, McGinn T, Davidson KW, et al. Presenting characteristics, comorbidities, and outcomes among 5700 patients hospitalized with COVID-19 in the New York City area. JAMA. 2020;323(20):2052-2059. Available from: https:// jamanetwork.com/journals/jama/fullarticle/2765184.

52. Inciardi RM, Adamo M, Lupi L, Cani DS, Di Pasquale M, Tomasoni D, et al. Characteristics and outcomes of patients hospitalized for COVID-19 and cardiac disease in Northern Italy. Eur Heart J. 2020;41(19):1821-9. Available from: https://academic.oup.com/eurheartj/article/41/19/1821/5834516.

53. Zaninotto M, Mion MM, Cosma C, Rinaldi D, Plebani M. Presepsin in risk stratification of SARS-CoV-2 patients. Clin Chim Acta. 2020;507:161-163. Available from: http://www.sciencedirect.com/science/article/pii/ S0009898120301753.

54. Yang $X, Y u Y, X u J$, Shu $H$, Xia J, Liu H, et al. Clinical course and outcomes of critically ill patients with SARS-CoV-2 pneumonia in Wuhan, China: a single-centered, retrospective, observational study. Lancet Respir Med. 2020. Elsevier. Available from: https://www.thelancet.com/journals/ lanres/article/PIIS2213-2600(20)30079-5/abstract.

55. Wu C, Hu X, Song J, Du C, Xu J, Yang D, et al. Heart injury signs are associated with higher and earlier mortality in coronavirus disease 2019 (COVID-19). medRxiv. 2020. Available from: http://medrxiv.org/content/ early/2020/02/29/2020.02.26.20028589.abstract.

56. Lapidus N, Zhou X, Carrat F, Riou B, Zhao Y, Hejblum G. Biased and unbiased estimation of the average lengths of stay in intensive care units in the COVID-19 pandemic. medRxiv. 2020. Available from: http:// medrxiv.org/content/early/2020/04/24/2020.04.21.20073916.abstract.

57. Murray CJ. Forecasting COVID-19 impact on hospital bed-days, ICU-days, ventilator-days and deaths by US state in the next 4 months. medRxiv. 2020. Available from: http://medrxiv.org/content/early/2020/03/30/2020. 03.27.20043752.abstract.

58. Zhou F, Yu T, Du R, Fan G, Liu Y, Liu Z, et al. Clinical course and risk factors for mortality of adult inpatients with COVID-19 in Wuhan, China: a retrospective cohort study. Lancet. 2020;395(10229):1054-62.

59. Davies NG, Kucharski AJ, Eggo RM, Gimma A, Group CCW, Edmunds WJ. The effect of non-pharmaceutical interventions on COVID-19 cases, deaths and demand for hospital services in the UK: a modelling study. medRxiv. 2020. Available from: https://www.medrxiv.org/content/10. 1101/2020.04.01.20049908v1.
60. Cai Q, Huang D, Ou P, Yu H, Zhu Z, Xia Z, et al. COVID-19 in a designated infectious diseases hospital outside Hubei Province, China. Allergy. 2020. Available from: https://onlinelibrary.wiley.com/doi/abs/10.1111/all.14309.

61. Cao B, Wang Y, Wen D, Liu W, Wang J, Fan G, et al. A trial of lopinavir-ritonavir in adults hospitalized with severe covid-19. N Engl J Med. 2020;382:1787-799.

62. Cao J, Tu WJ, Cheng W, Yu L, Liu YK, Hu X, et al. Clinical features and short-term outcomes of 102 patients with corona virus disease 2019 in Wuhan, China. Clin Infect Dis. 2020. Available from: https://academic.oup. com/cid/article/doi/10.1093/cid/ciaa243/5814897.

63. Chen T, Wu D, Chen H, Yan W, Yang D, Chen G, et al. Clinical characteristics of 113 deceased patients with coronavirus disease 2019 retrospective study. BMJ. 2020368. BMJ Publishing Group Ltd. Available from: https://www.bmj.com/content/368/bmj.m1091.

64. Chen J, Qi T, Liu L, Ling Y, Qian Z, Li T, et al. Clinical progression of patients with COVID-19 in Shanghai, China. J Infect. 2020;80(5):e1-e6. Available from: https://linkinghub.elsevier.com/retrieve/pii/ S0163445320301195.

65. Chen X, Zheng F, Qing Y, Ding S, Yang D, Lei C, et al. Epidemiological and clinical features of 291 cases with coronavirus disease 2019 in areas adjacent to Hubei, China: a double-center observational study. medRxiv. 2020. Available from: http://medrxiv.org/content/early/2020/03/06/2020. 03.03.20030353.abstract.

66. Cheng Y, Luo R, Wang K, Zhang M, Wang Z, Dong L, et al. Kidney impairment is associated with in-hospital death of COVID-19 patients. medRxiv. 2020. Available from: http://medrxiv.org/content/early/2020/ 02/20/2020.02.18.20023242.abstract.

67. Deng Y, Liu W, Liu K, Fang YY, Shang J, Zhou L, et al. Clinical characteristics of fatal and recovered cases of coronavirus disease 2019 (COVID-19) in Wuhan, China: a retrospective study. Chin Med J (Engl). 2020. Publish Ahead of Print. Available from: https://journals.Iww.com/ cmj/Fulltext/9000/Clinical_characteristics_of_fatal_and_recovered. 99319.aspx.

68. Ding Q, Lu P, Fan Y, Xia Y, Liu M. The clinical characteristics of pneumonia patients coinfected with 2019 novel coronavirus and influenza virus in Wuhan, China. J Med Virol. 2020. Available from: https:// onlinelibrary.wiley.com/doi/abs/10.1002/jmv.25781.

69. Du Y, Tu L, Zhu P, Mu M, Wang R, Yang P, et al. Clinical features of 85 fatal cases of COVID-19 from Wuhan: a retrospective observational study. Am J Respir Crit Care Med. 2020. American Thoracic Society - AJRCCM. Available from: https://www.atsjournals.org/doi/10.1164/rccm.202003-05430C.

70. Fan Z, Chen L, Li J, Cheng X, Yang J, Tian C, et al. Clinical features of COVID-19-related liver damage. Clin Gastroenterol Hepatol. 2020S1542356520304821. Available from: https://linkinghub.elsevier. com/retrieve/pii/S1542356520304821.

71. Liu J, Ouyang L, Guo P, Wu HS, Fu P, Chen YL, et al. Epidemiological, clinical characteristics and outcome of medical staff infected with COVID-19 in Wuhan, China: a retrospective case series analysis. medRxiv. 2020. Available from: http://medrxiv.org/content/early/2020/03/13/2020. 03.09.20033118.abstract.

72. Liu L, Gao JY. Clinical characteristics of 51 patients discharged from hospital with COVID-19 in Chongqing???China. medRxiv. 2020. Available from: http://medrxiv.org/content/early/2020/02/23/2020.02.20.20025536 abstract.

73. Mo P, Xing $Y$, Xiao $Y$, Deng $L$, Zhao Q, Wang $H$, et al. Clinical characteristics of refractory COVID-19 pneumonia in Wuhan, China. Clin Infect Dis. 2020;ciaa270:. Available from: https://doi.org/10.1093/cid/ ciaa270.

74. Pan F, Ye T, Sun P, Gui S, Liang B, Li L, et al. Time course of lung changes on chest CT during recovery from 2019 novel coronavirus (COVID-19) pneumonia. Radiology. 2020200370. Radiological Society of North America. Available from: https://pubs.rsna.org/doi/10.1148/radiol. 2020200370

75. Qi D, Yan X, Tang X, Peng J, Yu Q, Feng L, et al. Epidemiological and clinical features of 2019-nCoV acute respiratory disease cases in Chongqing municipality, China: a retrospective, descriptive, multiple-center study. medRxiv. 2020. Available from: http://medrxiv.org/ content/early/2020/03/03/2020.03.01.20029397.abstract.

76. Tang X, Du R, Wang R, Cao T, Guan L, Yang C, et al. Comparison of hospitalized patients with ARDS caused by COVID-19 and H1N1. Chest. 
2020. Available from: https://linkinghub.elsevier.com/retrieve/pii/ S0012369220305584.

77. Tian S, Chang Z, Wang Y, Wu M, Zhang W, Zhou G, et al. Clinical characteristics and reasons of different duration from onset to release from quarantine for patients with COVID-19 outside Hubei province, China. medRxiv. 2020. Available from: http://medrxiv.org/content/early/ 2020/03/23/2020.03.21.20038778.abstract.

78. Tian S, Zhu X, Sun X, Wang J, Zhou Q, Wang C, et al. Longitudinal analysis of laboratory findings during the process of recovery for patients with COVID-19. medRxiv. 2020. Available from: http://medrxiv.org/ content/early/2020/04/07/2020.04.04.20053280.abstract.

79. Wu J, Liu J, Zhao X, Liu C, Wang W, Wang D, et al. Clinical characteristics of imported cases of coronavirus disease 2019 (COVID-19) in Jiangsu Province: a multicenter descriptive study. Clin Infect Dis. 2020. Available from: https://academic.oup.com/cid/article/doi/10.1093/cid/ciaa199/ 5766408.

80. Wu C, Chen X, Cai Y, Xia J, Zhou X, Xu S, et al. Risk factors associated with acute respiratory distress syndrome and death in patients with coronavirus disease 2019 pneumonia in Wuhan, China. JAMA Intern Med. 2020. Available from: https://jamanetwork.com/journals/ jamainternalmedicine/fullarticle/2763184.

81. Wu F, Wang A, Liu M, Wang Q, Chen J, Xia S, et al. Neutralizing antibody responses to SARS-CoV-2 in a COVID-19 recovered patient cohort and their implications. medRxiv. 2020. Available from: https://www.medrxiv. org/content/10.1101/2020.03.30.20047365v2.

82. Xiao G, Hu H, Wu F, Sha T, Huang Q, Li H, et al. Acute kidney injury in patients hospitalized with COVID-19 in Wuhan, China: a single-center retrospective observational study. medRxiv. 2020. Available from: http:// medrxiv.org/content/early/2020/04/08/2020.04.06.20055194.abstract.

83. Xie H, Zhao J, Lian N, Lin S, Xie Q, Zhuo H. Clinical characteristics of non-ICU hospitalized patients with coronavirus disease 2019 and liver injury: a retrospective study. Liver Int. 2020. Available from: https:// onlinelibrary.wiley.com/doi/abs/10.1111/liv.14449.

84. Xu S, Fu L, Fei J, Xiang HX, Xiang Y, Tan ZX, et al. Acute kidney injury at early stage as a negative prognostic indicator of patients with COVID-19: a hospital-based retrospective analysis. medRxiv. 2020. Available from: http://medrxiv.org/content/early/2020/03/26/2020.03.24.20042408. abstract.

85. Yan D, Liu XY, Zhu YN, Huang L, Dan BT, Zhang GJ, et al. Factors associated with prolonged viral shedding and impact of Lopinavir/Ritonavir treatment in patients with SARS-CoV-2 infection. medRxiv. 2020. Available from: http://medrxiv.org/content/early/2020/ 03/30/2020.03.22.20040832.abstract.

86. Yuan J, Zou R, Zeng L, Kou S, Lan J, Li X, et al. The correlation between viral clearance and biochemical outcomes of 94 COVID-19 infected discharged patients. Inflamm Res. 2020. Available from: https://doi.org/ 10.1007/s00011-020-01342-0.

87. Zeng Z, Sha T, Zhang Y, Wu F, Hu H, Li H, et al. Hypertension in patients hospitalized with COVID-19 in Wuhan, China: a single-center retrospective observational study. medRxiv. 2020. Available from: http:// medrxiv.org/content/early/2020/04/11/2020.04.06.20054825.abstract.

88. Zhang G, Hu C, Luo L, Fang F, Chen Y, Li J, et al. Clinical features and outcomes of 221 patients with COVID-19 in Wuhan, China. medRxiv. 2020. Available from: http://medrxiv.org/content/early/2020/03/06/2020. 03.02.20030452.abstract.

89. Zhao W, Yu S, Zha X, Wang N, Pang Q, Li T, et al. Clinical characteristics and durations of hospitalized patients with COVID-19 in Beijing: a retrospective cohort study. medRxiv. 2020. Available from: http://medrxiv. org/content/early/2020/03/30/2020.03.13.20035436.abstract.

\section{Publisher's Note}

Springer Nature remains neutral with regard to jurisdictional claims in published maps and institutional affiliations. 